\title{
Expression of DREB-Like Genes in Coffea canephora and C. arabica Subjected to Various Types of Abiotic Stress
}

\author{
Luana Ferreira Torres ${ }^{1,2} \cdot$ Tharyn Reichel ${ }^{1,2}$ - Eveline Déchamp ${ }^{3} \cdot$ Sinara Oliveira de Aquino ${ }^{1,4}$. \\ Karoline Estefani Duarte ${ }^{1,4}$. Gabriel Sergio Costa Alves ${ }^{1,4}$ - Anderson Tadeu Silva ${ }^{2}$. Michelle Guitton Cotta ${ }^{1,4}$. \\ Tatiana Santos Costa ${ }^{1,4}$ • Leandro Eugenio Cardamone Diniz ${ }^{5}$. Jean-Christophe Breitler ${ }^{3}$. Myriam Collin ${ }^{6}$. \\ Luciano Vilela Paiva $^{1}$. Alan Carvalho Andrade ${ }^{1,2,4} \cdot$ Hervé Etienne $^{3} \cdot$ Pierre Marraccini $^{4,7,8}$ (D)
}

Received: 19 December 2018 / Accepted: 18 February 2019

(C) Springer Science+Business Media, LLC, part of Springer Nature 2019

\begin{abstract}
The aim of this work was to study the regulation of coffee $D R E B$-like genes in leaves of $C$. arabica subjected to cold, heat, low relative humidity, exogenous abscisic acid and high light stress, as well as in leaves and roots of drought-tolerant and droughtsusceptible clones of Coffea canephora subjected to water limitation. In C. arabica, CaERF017 was the most expressed gene under low temperatures and relative humidity, while low humidity and high temperatures up-regulated the expression of CaERF053 and CaERF014, respectively. Under water limitation, CcDREB1B, CcRAP2.4, CcERF027, CcDREB1D and CcTINY were the most expressed genes mainly in leaves of drought-tolerant $C$. canephora. On the other hand, expression of the CcERF016, CcRAP2.4 and $C C D R E B 2 F$ genes was highly up-regulated under water limitation in the roots of drought-susceptible $C$. canephora clone 22 . We previously reported fine-tuned regulation of CCDREB1D promoter haplotypes (HP15, HP16 and HP17) in transgenic C. arabica subjected to low humidity. Here, we investigated the regulation of these haplotypes under high light, cold, heat, and abscisic acid (ABA) stress. In apical buds and leaf guard cells, GUS-stained percentages were higher in pHP16L-transformed plants subjected to low humidity, high light and ABA stress than in $\mathrm{PHP} 17 \mathrm{~L}$ - and pHP15L-transformed plants. We also reported up-regulated expression of the endogenous CaDREB1D gene for both the cold and low humidity in leaves of pHP16L-transformed $C$. arabica suggesting a key role of this gene in controlling the responses of coffee plants to abiotic stress probably through an ABA-dependent pathway.
\end{abstract}

Keywords Abiotic stress - Abscisic acid - coffee - DREB - gene expression - promoter

Key message: $D R E B$-like genes are differentially expressed in drought-tolerant and susceptible clones of $C$. canephora subjected to different abiotic stress. In C. arabica, both cold, low humidity and ABA up-regulate $C a D R E B 1 D$ gene expression.

Communicated by: Philippe Lashermes

Electronic supplementary material The online version of this article (https://doi.org/10.1007/s12042-019-09223-5) contains supplementary material, which is available to authorized users.

Pierre Marraccini

marraccini@cirad.fr

1 Universidade Federal de Lavras, Campus UFLA, Lavras, MG 37200-000, Brazil

2 Embrapa Café, INOVACAFÉ, Campus UFLA, Lavras, MG 37200-000, Brazil

3 UMR IPME, CIRAD, IRD, University of Montpellier, F-34394 Montpellier, France

4 EMBRAPA Recursos Genéticos e Biotecnologia (LGM), Parque EB, Brasilia, DF 70770-917, Brazil
5 EMBRAPA Tabuleiros Costeiros, Aracaju, SE 49025-040, Brazil

6 UMR DIADE, CIRAD, IRD, University of Montpellier, F-34394 Montpellier, France

7 UMR AGAP, CIRAD, IRD, INRA, University of Montpellier, F-34398 Montpellier, France

8 Present address: CIRAD, UMR IPME (Univ. Montpellier, CIRAD, IRD), Agricultural Genetics Institute, LMI RICE2, Pham Van Dong street KM2, Tuliem, Hanoi, Vietnam 


\section{Introduction}

As for many other plant commodities, climate change is likely to affect coffee production in the coming decades by increasing abiotic stress periods (drought, high temperatures), pests and diseases (Jaramillo et al. 2011), reducing flowering (Imbach et al. 2017), altering plant development (DaMatta and Ramalho 2006), as well as fruit ripening and quality (Silva et al. 2005; Vinecky et al. 2017), thereby making it increasingly difficult to maintain coffee in many traditional coffee regions (Davis et al. 2012; Bunn et al. 2015; Van der Vossen et al. 2015). For these reasons, research on coffee adaptation to abiotic stress is an urgent priority, as is the need for alternative and faster breeding methods (Andrade 2018).

Plants react to biotic and abiotic stress by producing hormones such as abscisic acid (ABA), salicylic acid and jasmonic acid. These hormones promote the expression of transcription factors (TFs), which themselves activate the expression of many genes involved in cell protection, detoxification and repair, among other things (Atkinson and Urwin 2012). Of these TFs, DREB (Dehydration Responsive Element Binding) proteins have been extensively studied because they respond to a variety of stresses (Shinozaki and Yamaguchi-Shinozaki 2007; Khan 2011). Their corresponding genes belong to the AP2/ERF (APETALA 2/ethylene-responsive factor) family characterized by the presence of conserved protein domains used for their classification in higher plants (Sakuma et al. 2002; Nakano et al. 2006; Canella et al. 2010). In terms of their regulation, $D R E B$ genes are commonly divided into two homologous gene families, $D R E B 1$ and $D R E B 2$, the first being induced mostly by cold and the second by dehydration, high salinity and heat stress, for example (Shinozaki and Yamaguchi-Shinozaki 2007; Lata and Prasad 2011). Based on the completion of the C. canephora genome (Denoeud et al. 2014), and as previously observed for AtDREB genes in Arabidopsis (Nakano et al. 2006), Alves (2015) recently identified thirty-one coffee $D R E B$-like genes phylogenetically divided into four subgroups (I, II, III and IV) containing five, six, twelve and eight genes, respectively (Supplementary Fig. S1).

In order to study the genetic determinism of drought tolerance in coffee, we previously reported the identification of more than eighty candidate genes in different tissues (leaves, roots, plagiotropic buds) of drought-tolerant $\left(\mathrm{D}^{\mathrm{T}}\right)$ and drought-susceptible $\left(\mathrm{D}^{\mathrm{S}}\right)$ plants of $C$. canephora (Vinecky et al. 2012; Marraccini et al. 2012; Vieira et al. 2013) and C. arabica (Freire et al. 2013; Mofatto et al. 2016) displaying differential expression profiles under drought stress. Among them, $C C D R E B 1 D$ (also known as C-repeat-binding factor 4 CBF4) attracted particular attention because it was highly upregulated under drought stress in the leaves of $\mathrm{D}^{\mathrm{T}}$ clones (mainly in clone 14 and to a lesser extent in clones 73 and 120) of $C$. canephora Conilon, while its expression was barely increased under water limitation in the leaves of $\mathrm{D}^{\mathrm{S}}$ clone 22
(Marraccini et al. 2012; Vieira et al. 2013). In higher plants, $D R E B 1 D$ gene expression has been reported to be upregulated by development and several stress conditions, such as drought in Arabidopsis (Haake et al. 2002), as well as by low temperatures, drought, and salinity in Vitis (Xiao et al. 2008; Zandkarimi et al. 2015) and in Medicago truncatula (Li et al. 2011). In several genetically engineered plants, overexpression of the $D R E B 1 D / C B F 4$ gene has been shown to increase tolerance of drought, cold and/or salt (Haake et al. 2002; Li et al. 2011; Guttikonda et al. 2014), highlighting its key role in plant responses to abiotic stress. In coffee, recent studies reported up-regulated expression of the DREBID gene in $C$. canephora leaves subjected to a sharp drop in relative humidity (RH) (Thioune et al. 2017), as well as in C. arabica leaves subjected to low RH, and to high and low temperatures (Alves et al. 2018). An in-depth study of the CCDREB1D promoters in $\mathrm{D}^{\mathrm{T}}$ clone 14 and $\mathrm{D}^{\mathrm{S}}$ clone 22 revealed the existence of three haplotypes (HP15, HP16 and HP16) diverging from each other in several single nucleotide polymorphisms (SNPs) and insertions/deletions (INDELs), with HP15 being common to the two clones, while HP16 and HP17 were specific to clones 14 and 22, respectively (Alves et al. 2017). The genetic diversity of DREB1D promoters demonstrated that HP15 and HP16 haplotypes clustered in C. canephora genetic sub-group 1 (SG1) of the Congolese group, considered highly tolerant to drought, while HP17 was closer to genotypes of Congolese sub-group 2 (SG2) considered as susceptible (Alves et al. 2018). A functional analysis of these haplotype transgenic plants of $C$. arabica var. Caturra subjected to water limitation (mimicked by low RH and polyethylene glycol [PEG] osmotic treatments) also showed that HP16 was able to drive expression of the uidA reporter gene in leaf mesophyll and guard cells more strongly and earlier than the HP15 and HP17 haplotypes (Alves et al. 2017). Using the same constructions in transgenic tobacco, up-regulated expression of the uidA reporter gene under the control of the HP15 and HP16 haplotypes was observed under cold stress, but not under dehydration and heat shock (de Aquino et al. 2018). The nucleic polymorphism detected between these promoter haplotypes might explain differences in the fine-tuning of their regulation under water limitation in both $C$. arabica and N. tabacum transgenic plants.

Based on this information, the main objectives of this work were (i) to study the regulation of previously identified coffee $D R E B$-like genes in leaves and roots of $\mathrm{D}^{\mathrm{T}}$ and $\mathrm{D}^{\mathrm{S}}$ clones of C. canephora subjected to water limitation, and in leaves of C. arabica subjected to cold, heat, low RH, exogenous ABA and high light stress (mimicked by high irradiance) treatments and (ii) to gain a clearer understanding of the tissue location, regulation and activity of $C C D R E B 1 D$ promoter haplotypes by analysing their ability to regulate the expression of the uidA reporter gene in C. arabica transgenic plants subjected to the similar abiotic stress. 


\section{Materials and Methods}

\section{DREB-Like Gene Nomenclature}

The thirty-one $D R E B$-like orthologous genes were previously identified in the $C$. canephora genome and manually edited in the Coffee Genome Hub (http://coffee-genome.org/) (Alves 2015). These genes were divided into four subgroups (SG) named I, II, III and IV (Supplementary Fig. S1 and Table 1): 5 in SG-I (Cc03_g07870 [ERF062], Cc05_g06840 [ERF053], Cc07_g15390[ERF060], Cc08_g15980 [ERF061] and Cc10_g07460[RAP2.4]), 6 in SG-II (Cc06_g12520 [ERF017], Cc07_g06220[RAP2.10],Cc08_g07780 [ERF016], Cc10_g04710[RAP2.1], Cc10_g09120 [ERF013] and Cc10_g10960 [ERF014]), 12 in SG-III (Cc01_g09680 [DREB1C], Cc02_g03420 [ERF027], Cc02_ g03430 [DREB1D], Cc02_g24810 [ERF034], Cc02_g39490 [ERF023],Cc04_g02760[ERF043],Cc06_g05340 [ERF024],Cc06_g10260 [DREB3],Cc08_g09520 [TINY], Cc08_g12160 [ERF039], Cc08_g13960 [DREB1B] and $C c 08 \_g 13970$ [ERF025]) and 8 in SG-IV (Cc02_g05970 [DREB2A.1], Cc02_g06230 [ABI4],Cc06_g00780 [DREB2C], Cc06_g16660[DREB2F],Cc09_g03140 [DREB2G], Cc10_g02270 [DREB2D], Cc10_g14150 [DREB2A.2] and Cc_10g14160 [DREB2A.3]). The nomenclature for $D R E B$-like genes uses the $C a$ and $C c$ prefixes for C. arabica and C. canephora, respectively.

\section{Plant Materials}

The drought-tolerant $\left(\mathrm{D}^{\mathrm{T}}: 14,73\right.$ and 120$)$ and droughtsusceptible $\left(\mathrm{D}^{\mathrm{S}}\right.$ : 22) clones of $C$. canephora Conilon were selected at the Institute for Research and Rural Assistance (Incaper, Vitoria, Espirito Santo, Brazil) (Ferrão et al. 2000), propagated by cuttings and grown (in 2009) in greenhouse (Federal University of Viçosa-UFV, Minas Gerais, Brazil) conditions $\left[25^{\circ} \mathrm{C}, 70 \%\right.$ relative, average mid-day photosynthetic photon flux (PPF) of $900 \mu \mathrm{mol} \mathrm{m} \mathrm{m}^{-2} \mathrm{~s}^{-1}$ / sodium lamps] individually in pots of 121 of a mixture of soil, sand, and manure $(3: 1: 1, v / \mathrm{v} / \mathrm{v})$. After 6 months, plants were subjected to water limitation (WL) by water withdrawal (NI) until reaching a $\Psi_{p d}$ (predawn leaf water potential) of $-3.0 \mathrm{MPa}$ (Marraccini et al. 2011, 2012; Vieira et al. 2013). For C. arabica var. Caturra, young plants (around $4 \mathrm{~cm}$ in height and with 4-5 leaf pairs) transformed by the pHP15L, pHP16L, pHP17L, pBI121 (CaMV35S::uidA, positive control) and pBI101 (uidA-promoterless, negative control) constructions were previously described by Alves et al. (2017) and cultivated in growth chambers (in 2014) at IRD (Institut de recherche pour le développement, Montpellier, France). For each construction and transgenic line, only plants harbouring a single insertion were conserved for further bioassays. Prior to stress, C. arabica plants were cultivated in Gerber flasks on MS
(Murashige and Skoog 1962) medium in a growth chamber under a 12-h-light/12-h-dark (light from 08:00 am to 08:00 $\mathrm{pm}$ ) photoperiod $\left(70 \mu \mathrm{mol} \mathrm{m}{ }^{-2} \mathrm{~s}^{-1}\right.$ photon flux density / LED lamps) at $26{ }^{\circ} \mathrm{C}$ and $80 \%$ relative humidity ( $\left.\mathrm{RH}\right)$, as described by Etienne (2005).

\section{Abiotic Stress Experiments on C. arabica}

For the low relative humidity (LH), cold (LT, low temperature), heat (HT, high temperature), high light stress (HL) and abscisic acid (ABA) experiments, four plants (one plant per Gerber flask forming an independent replicate) derived from independent transformation events were studied. To minimize possible effects of the circadian clock, all these experiments began at around 10:00 am (after a $2 \mathrm{~h}$ light period) and were applied for $12 \mathrm{~h}$, except for the ABA treatment, which was applied for periods of 24 and $48 \mathrm{~h}$. The stress conditions were as follows:

- Low relative humidity assay (LH): the a low (9\%) humidity was created using $500 \mathrm{ml}$ of potassium hydroxide $(\mathrm{KOH})$ supersaturate solution poured into the lower compartment of a temporary immersion bioreactor (Matis ${ }^{\circledR}$, CID Plastiques, France) (Supplementary Fig. S2). Transformed coffee plants were placed in the upper compartment over $55 \mathrm{~mm}$ Petri dishes with their upper part exposed to the outside environment and their radicles immersed in MS medium with activated charcoal $\left(1 \mathrm{~g} \mathrm{l}^{-1}\right)$ through a small hand-made hole in the Petri dish cover (one plant per Petri dish). To avoid any exchange of water vapour between the MS medium and the atmosphere outside the bioreactor, the hand-made hole was closed with high-vacuum silicone grease (Dow Corning ${ }^{\circledR}$, Sigma) and the Petri dishes were sealed with plastic film. Batches of 10 plants were incubated in the bioreactor at $9 \% \mathrm{RH}$ and $26{ }^{\circ} \mathrm{C}$. Leaf samples were harvested at 10:00 pm (after $2 \mathrm{~h}$ of dark).

- Cold stress (LT: low temperature): plants were transferred from the growth chamber $\left(26^{\circ} \mathrm{C}\right)$ into a cold chamber at $5{ }^{\circ} \mathrm{C}$ without lighting. Leaf samples were harvested after being $12 \mathrm{~h}$ in dark.

- Heat stress (HT: high temperature): plants were transferred from the growth chamber $\left(26^{\circ} \mathrm{C}\right)$ to an oven heated to $40{ }^{\circ} \mathrm{C}$ without lighting. Leaf samples were harvested after being $12 \mathrm{~h}$ in dark.

- High light stress (HL): the light intensity of the growth chamber was suddenly increased from 70 to $200 \mu \mathrm{M} \mathrm{m}^{-2} \mathrm{~s}^{-1}$ (without a spectrum change). Leaf samples were harvested at 10:00 pm (after $2 \mathrm{~h}$ of dark).

- Exogenous abscisic acid (ABA): plants were transferred from the ' $M$ ' maturation medium (Etienne 2005) into Gerber flasks containing the same medium supplemented with $10 \mu \mathrm{M}$ ABA (Sigma Aldrich, St Louis, USA). 


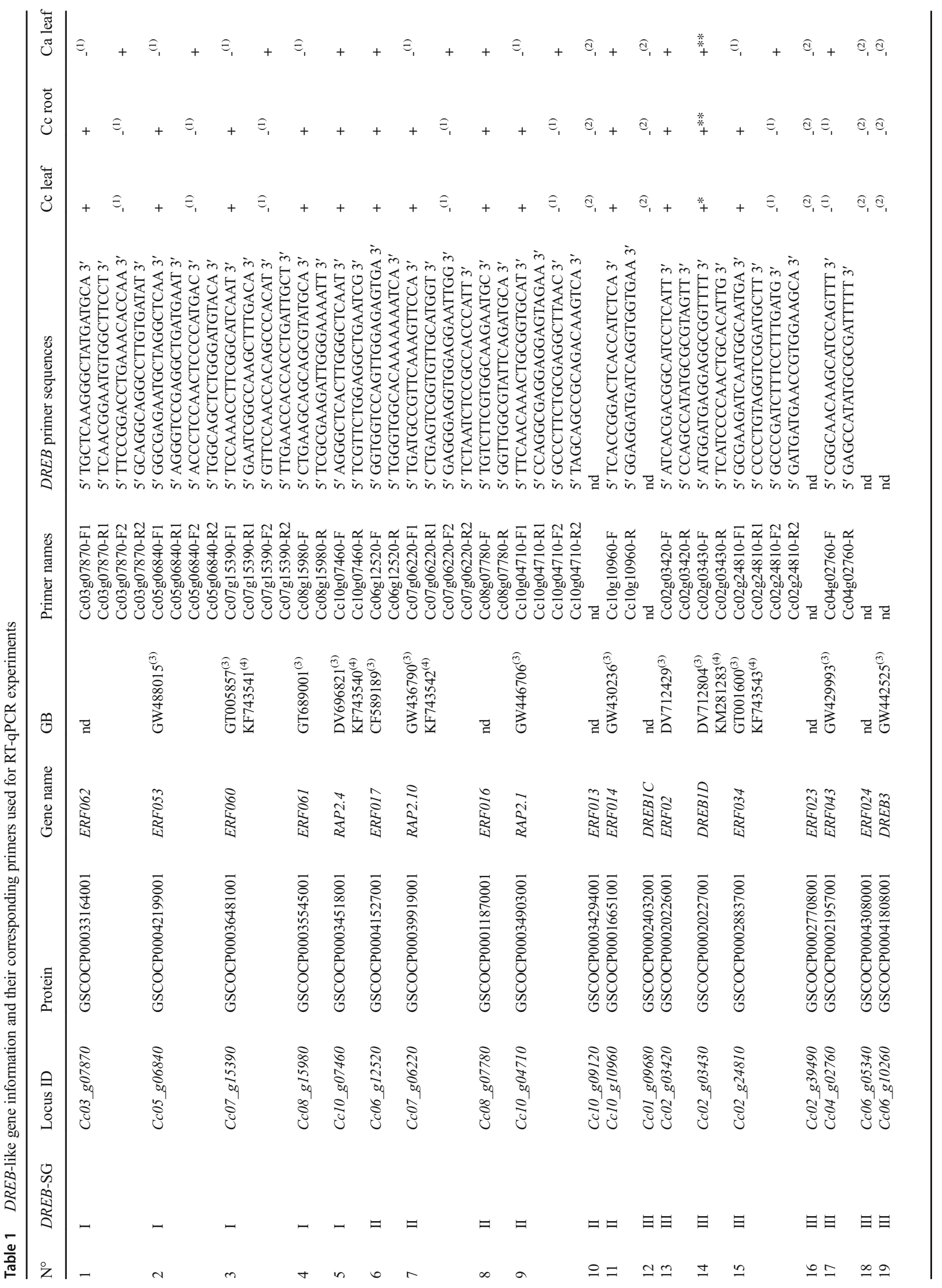




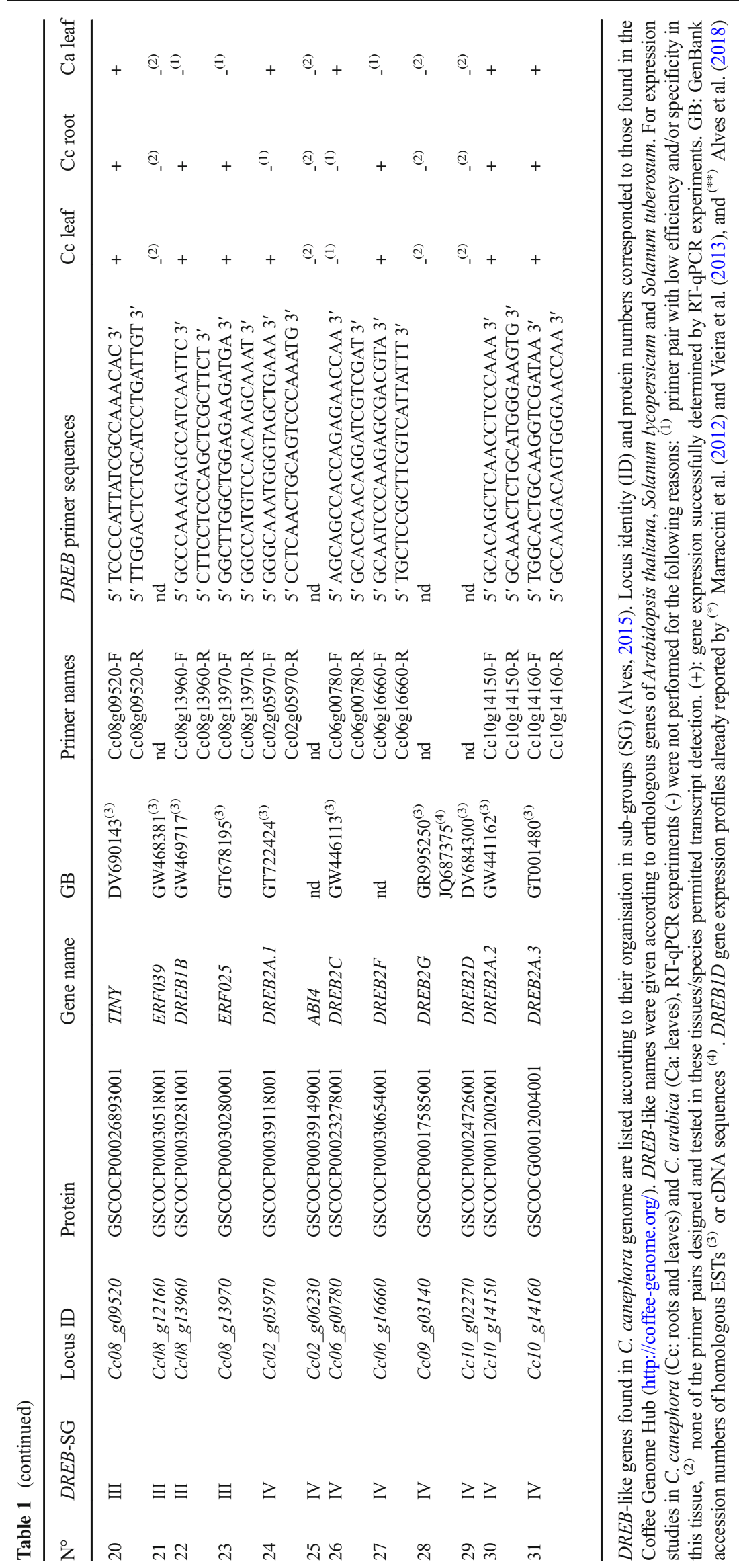




\section{$\beta$-Glucuronidase (GUS) Staining}

Following stress, transgenic coffee plants (four biological replications for each construction) were tested by GUS staining. Leaves, apical buds and roots were immersed in staining solution $(100 \mathrm{mM}$ sodium phosphate buffer, $\mathrm{pH}$ 7.2, $10 \mathrm{mM}$ sodium ethylenediaminetetraacetic acid, $0.1 \%$ Triton $\mathrm{X}-100,1 \mathrm{mg} \mathrm{ml}^{-1}$ 5-bromo-4-chloro-3indolyl-D-glucuronic acid [Sigma] and $2.5 \mathrm{mM}$ potassium ferricyanidine), followed by vacuum infiltration for $10 \mathrm{~min}$, incubation at $37{ }^{\circ} \mathrm{C}$ for $24 \mathrm{~h}$, then rinsing with $70 \%$ ethanol. The GUS-stained samples were fixed in fixative (50\% methanol and $10 \%$ acetic acid) at $4{ }^{\circ} \mathrm{C}$ for $24 \mathrm{~h}$, rinsed with water, then dehydrated for $10 \mathrm{~min}$ in $50 \%$ ethanol, $10 \mathrm{~min}$ in $70 \%$ ethanol and $10 \mathrm{~min}$ in $90 \%$ ethanol. After observation with a Nikon binocular SMZ 1500 loupe, samples were embedded in $6 \%$ agarose for subsequent sectioning in a Microm HM650V vibratome. For bright field microscopy observation, $50-\mu \mathrm{m}$ thick leaf sections were examined using a DM600 Leica microscope (Leica Microsystems GmbH, Wetzlar, Germany). Pictures were taken with a Retiga 2000R camera (G-Imaging Co., Wetzlar, Germany).

\section{Proportion of GUS-Stained Guard Cells in Abiotic Stress Assays}

For bright field microscopy observation, GUS-stained leaves were kept in fixative (50\% methanol and $10 \%$ acetic acid) at $4{ }^{\circ} \mathrm{C}$ for $24 \mathrm{~h}$. The tissues were rinsed with water and incubated for at least 3 days in clearing solution (chloral hydrate:glycerol:water solution $(4: 1: 2, v / \mathrm{v} / \mathrm{v}))$ to remove all leaf pigments. Prior to observation, the tissues were rinsed with $70 \%$ ethanol and assembled on microscope slides. Whole leaves were examined using a DM600 Leica microscope. The proportion of GUS-stained guard cells on the abaxial epidermis of coffee leaves was calculated to estimate the activity of $C C D R E B 1 D$ promoter haplotypes. The proportion of GUS-stained guard cells ( $p$ ) was obtained by $p=x / n$, where $\mathrm{x}$ is the number of stained guard cells and $\mathrm{n}$ the total number of guard cells $( \pm 150)$ observed per leaf. These values were assessed in $24 \times 36 \mathrm{~mm}$ areas distributed in six pre-delimited leaf zones. For each pHP construction, four leaves from plants of four independent transformation events were sampled for each type of abiotic stress.

\section{RNA Extraction and Real-Time Quantitative PCR Assays}

For expression analyses in C. canephora, roots and fully expanded leaves $(8-15 \mathrm{~cm}$ long) from the third or fourth pair from the apex of plagiotropic branches localised in the third upper part of the plant canopy, were collected at daytime (between
10:00 am and noon). Expression analyses in C. arabica var. Caturra were performed in pHP16L-transformed plants using well-developed orthotropic leaves (1-2 cm long). All these samples were taken in triplicate, immediately frozen in liquid nitrogen and stored at $-80{ }^{\circ} \mathrm{C}$ for RNA extraction. Total RNA was extracted from tissues ground in liquid nitrogen and treated as described by Marraccini et al. (2011) for C. canephora (root and leaf) and Breitler et al. (2016) for C. arabica (leaf). RNA was quantified using a NanoDrop ${ }^{\mathrm{TM}} 1000$ Spectrophotometer (Waltham, MA, USA). For real-time quantitative PCR, the firststrand cDNA was synthesized using $1 \mu \mathrm{g}$ of total RNA, the ImProm-II Reverse Transcription System and oligo(dT15) according to the manufacturer's recommendations (Promega, Madison, WI, USA). Real-time quantitative PCR (RT-qPCR) experiments were carried out using the protocol recommended for the use of a 7500 Fast Real-Time PCR System (Applied Biosystems, Foster City, CA, USA) as previously described by Marraccini et al. (2012). DREB primers (Table 1) were designed using Primer Express software (Applied Biosystems) and were preliminarily tested for their specificity and efficiency against a cDNA mixture from roots and leaves. Data were analysed using 7500 Fast Software v2.0.6 (Applied Biosystems) to determine cycle threshold $(\mathrm{Ct})$ values. Gene expression levels were normalized to the expression level of the CaGAPDH (de Carvalho et al. 2013) and CcUBQ10 (Barsalobres-Cavallari et al. 2009) reference genes (Table 2), in C. arabica and C. canephora, respectively.

\section{Statistics}

The significance of expression level differences was evaluated using the pairwise Wilcoxon rank test (nonparametric test).

Table 2 List of primers used in this study. Primer pairs used in RTqPCR experiments to analyse the expression of the uidA (GUS-F/R) and CaDREB1D (DREBA09-F/R, Alves et al. 2017) genes in pHP16Ltransformed plants of $C$. arabica var. Caturra (see Fig. 8). The primer pair GAPDH-F/R and BUBI-F/R were used to amplify the transcripts of the $C a G A P D H$ and $C c U B Q 10$ used as reference genes in C. arabica and C. canephora, respectively

\begin{tabular}{ll}
\hline Primers & Sequences \\
\hline GUS-F & 5' GCACTAGCGGGACTTTGCAA 3' \\
GUS-R & 5' CGCGAAGCGGGTAGATATCA 3' \\
DREBA09-F & 5' CAATGCCTGCAAAGCCAATTA 3' \\
DREBA09-R & 5' TTTTCCTGCCTGCACGTTTC 3' \\
GAPDH-F & 5' TTGAAGGGCGGTGCAAA 3' \\
GAPDH-R & 5' AACATGGGTGCATCCTTGCT 3' \\
BUBI-F & 5'-AAGACAGCTTCAACAGAGTACAGCAT-3' \\
BUBI-R & 5'-GGCAGGACCTTGGCTGACTATA-3' \\
\hline
\end{tabular}




\section{Results}

\section{Expression of DREB-Like Genes in C. arabica and $C$. canephora Subjected to Different Types of Abiotic Stress}

The expression profiles of DREB-like genes were analysed (1) in leaves of $C$. arabica subjected to cold (LT: low temperature), heat (HT: high temperature), low humidity (LH), ABA and high light (HL) treatments and (2) in leaves (L) and roots $(\mathrm{R})$ of drought-tolerant $\left(\mathrm{D}^{\mathrm{T}}\right)$ and drought-susceptible $\left(\mathrm{D}^{\mathrm{S}}\right)$ clones of $C$. canephora subjected (NI) or not (I: control) to water limitation (WL).

Whatever the primer pairs tested, we were unable to detect expression of ERF013, DREB1C, ERF023, ERF024,DREB 3, ERF039, ABI4, DREB2G and $D R E B 2 D$ genes in either $C$. arabica or $C$. canephora
(Table 1). While expressed in C. canephora, expression was not detected for CaERF061, CaDREB1B, CaERF025 and $C a D R E B 2 F$ genes in $C$. arabica. On the contrary, expression of ERF043 and DREB2C genes was observed in $C$. arabica but not in C. canephora. For the remaining $D R E B$-like genes, the gene expression profiles obtained in C. $\operatorname{arabica}(\mathrm{L})$ and/or C. canephora (L and $\mathrm{R})$ are described below.

\section{- Expression of DREB-like genes in C. arabica leaves subjected to cold, heat, low humidity, $A B A$ and high light treatments}

The expression of DREB-like genes in leaves of C. arabica var. Caturra transformed by $\mathrm{pHP} 16 \mathrm{~L}$ and subjected to different abiotic stress was analysed by RT-qPCR (Fig. 1). Under stress-free conditions (NS), the expression of all $D R E B$-like genes was barely detected. For some
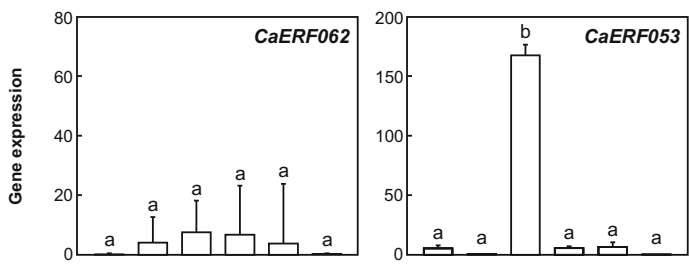

LT HT LH AB HL NS
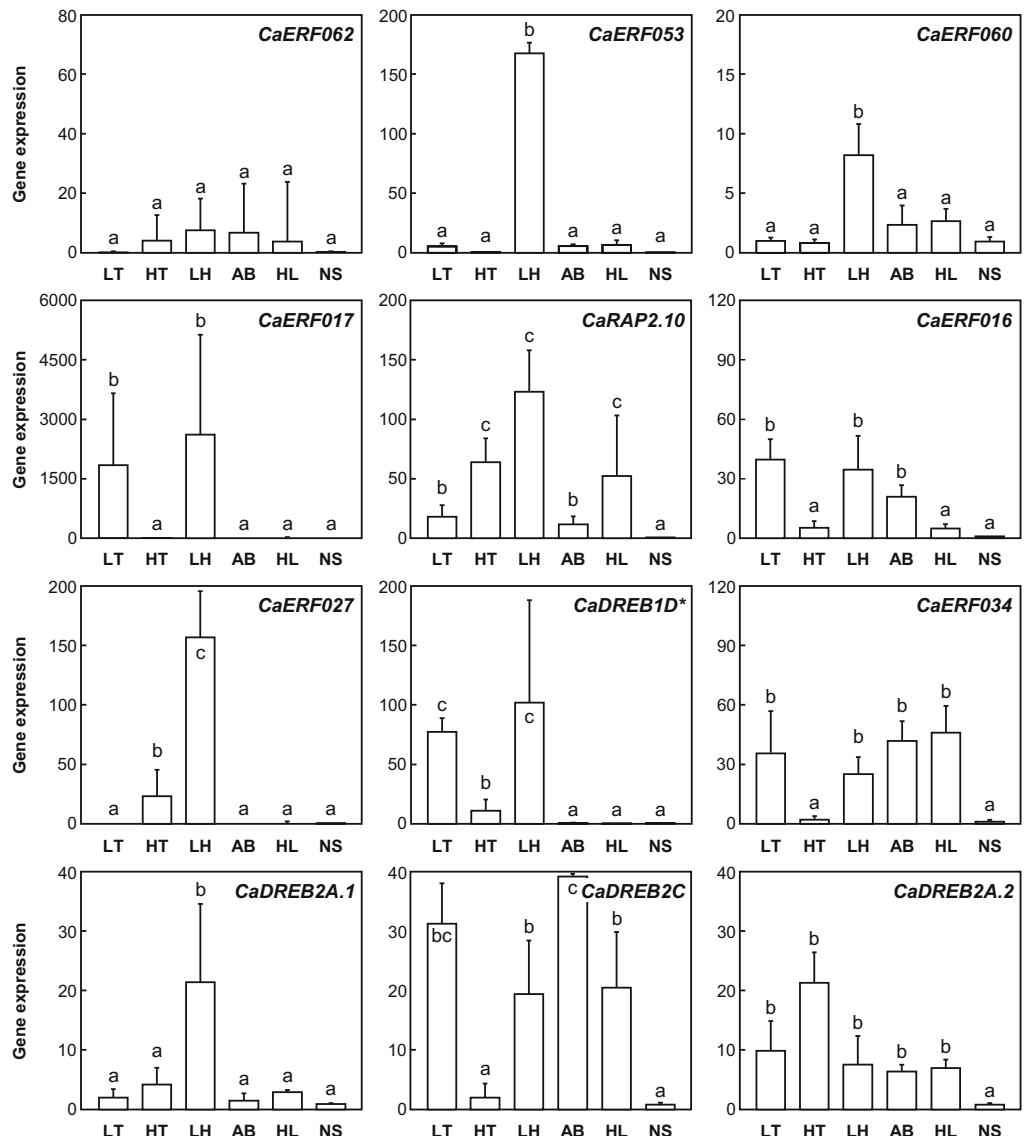

LT HT LH AB HL NS
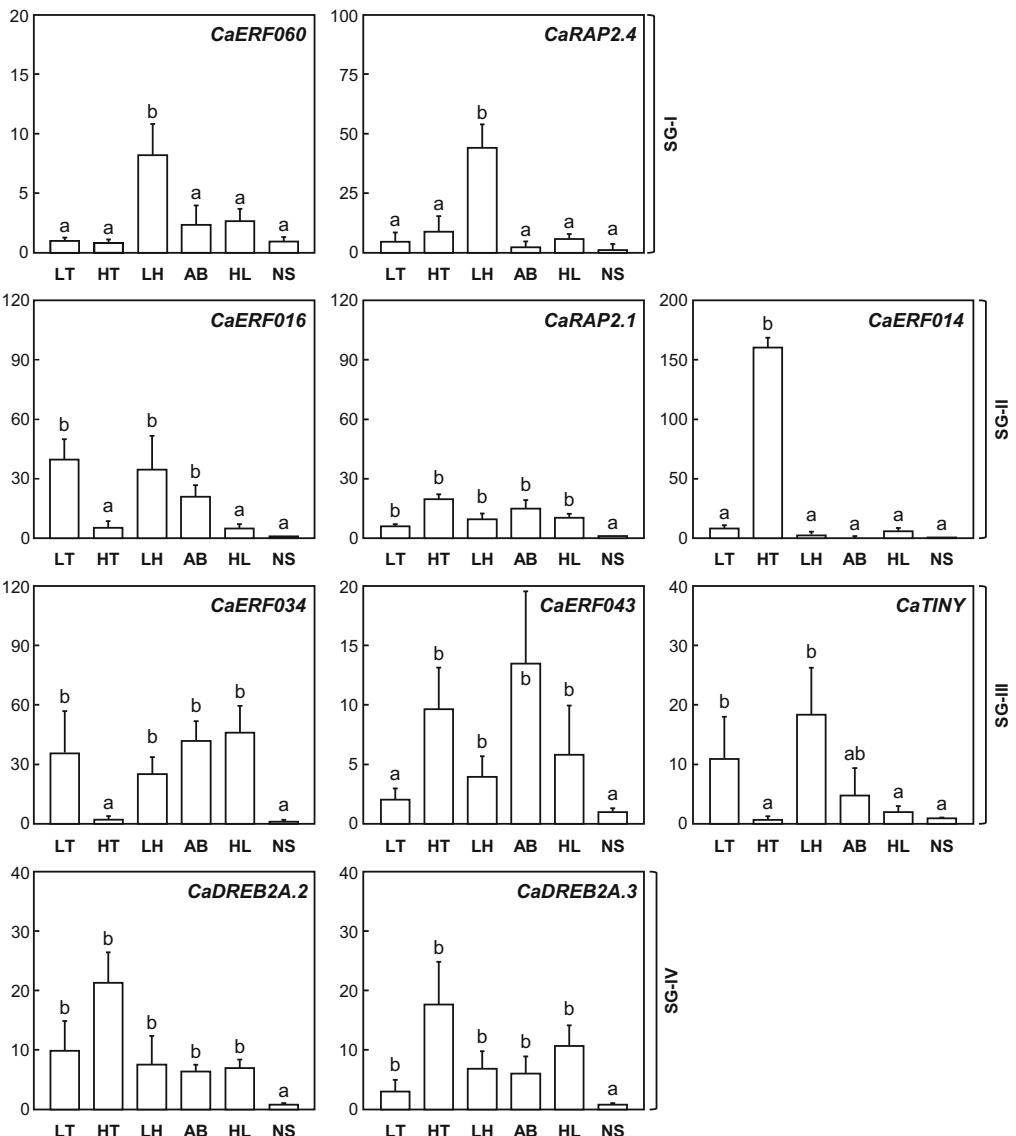

LT HT LH AB HL NS
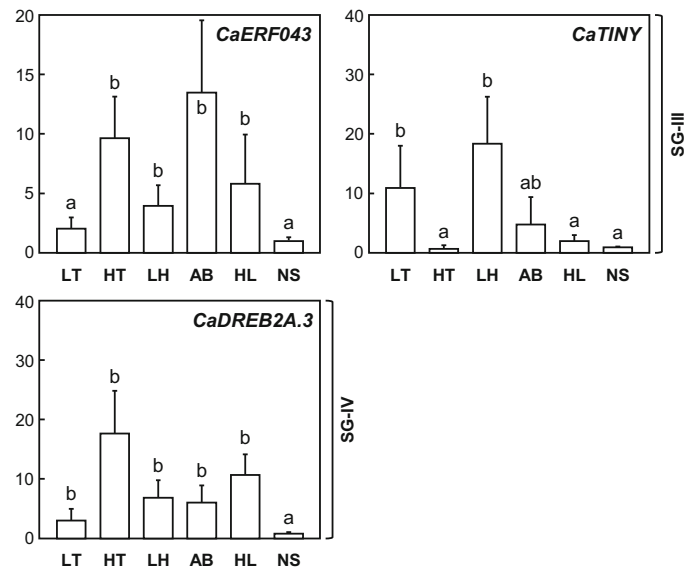

(relative expression $=1$ ). $D R E B$ sub-groups $(\mathrm{SG})$ are indicated. Transcript abundances were normalized using the expression of the $\mathrm{CaGAPDH}$ gene as the endogenous control. $\left(^{*}\right)$ : the $C a D R E B 1 D$ expression profile, already published by Alves et al. (2018), is shown in order to be compared with expression profiles of other $D R E B$-like genes. Treatments sharing the same letter are not significantly different
Fig. 1 Expression of DREB-like genes in leaves of $C$. arabica Caturra transformed by pHP16L and subjected to low (LT) and high (HT) temperatures, low humidity (LH), ABA treatment (AB) and high light stress (HL). Gene names are indicated in the histograms. Expression values corresponding to the mean of three biological and technical replications $( \pm \mathrm{SD})$ are expressed in fold change relative to the expression level of NS (no stress) sample used as the reference sample 
genes, expression was up-regulated by a unique stress. This was the case of SG-I genes CaERF053,CaERF060, CaRAP2.4 and SG-III gene CaDREB2A. 1 which were upregulated specifically by LH treatment and of CaERFO14 gene specifically up-regulated by HT. CaERF027 was the unique gene up-regulated by both LH (highly) and HT (moderately). LT and LH conditions highly up-regulated CaERF017 that presented the highest levels of gene expression. In addition to $\mathrm{LT}$ and $\mathrm{LH}$ treatments, CaDREBID and CaTINY genes were also weakly upregulated by $\mathrm{HT}$ and $\mathrm{ABA}$, respectively. Regarding the genes moderately induced by stress, CaRAP 2.10 was upregulated by HT, LH and HL treatments, CaERF016 by LT, LH and ABA, and CaERF034 by LT, LH, ABA and HL. The expression profiles of remaining genes were considered as weakly up-regulated by the different abiotic treatments.

\section{- Expression of DREB-like genes in C. canephora sub- jected to water limitation}

Expression of DREB-like genes was analysed independently in leaves and roots of drought-tolerant $\left(\mathrm{D}^{\mathrm{T}}\right)$ clones 14, 73 and 120, and drought- susceptible $\left(\mathrm{D}^{\mathrm{S}}\right)$ clone of C. canephora subjected (NI) or not (I) to water limitation (WL).

In the leaves of $C$. canephora clones, the genes most expressed were $C C D R E B 1 B$ and $C c T I N Y$, which were upregulated under WL conditions in both $\mathrm{D}^{\mathrm{T}}$ and $\mathrm{D}^{\mathrm{S}}$ clones (Fig. 2). However, WL up-regulated the expression of CcERF053, CcRAP2.4, CcERF017, CcERF014, $C C E R F 027$ and $C C D R E B 1 D$ specifically in leaves of all $\mathrm{D}^{\mathrm{T}}$ clones but not in those of $\mathrm{D}^{\mathrm{S}}$ clone 22. An inverse situation was observed for CcERF062 for which its expression was higher in clone 22 than in the $\mathrm{D}^{\mathrm{T}}$ clones under WL. Water limitation also up-regulated the expression of $C C R A P 2.10$ and $C C E R F 014$ genes in leaves of $\mathrm{D}^{\mathrm{T}}$ clone 14 but not in those of $\mathrm{D}^{\mathrm{T}}$ clones 73 and 120 . For the remaining genes, expression profiles did not undergo significant variations by WL.

In roots, CcRAP2.4, CCERF016 and CCDREB2F were the most overexpressed $D R E B$-like genes under WL (Fig. 3). Under this condition, it is worth noting that the expression of these genes was weak (or even undetectable) in all the $\mathrm{D}^{\mathrm{T}}$ clones, but greatly and specifically induced in $\mathrm{D}^{\mathrm{S}}$ clone 22. Water limitation also up-regulated the expression of CcERF061 in both $\mathrm{D}^{\mathrm{T}}$ and $\mathrm{D}^{\mathrm{S}}$ clones, CcTINY in $\mathrm{D}^{\mathrm{T}}$ clone 14, and CCDREB2A.2 in $\mathrm{D}^{\mathrm{T}}$ clone 120 . On the other hand, and whatever the clones, gene expression was considered as not significantly altered by WL for all remaining genes.

\section{GUS Enzymatic Activity Regulated by the DREB1D Promoter Haplotypes under Different Types of Abiotic Stress}

Regulation of the HP15, HP16 and HP17 promoter haplotypes of the $C C D R E B 1 D$ gene was studied by analysing GUS enzyme activity in leaves, apical buds and roots of $C$. arabica transgenic plants subjected to different types of abiotic stress (Fig. 4). Whatever the stress applied, strong GUS staining was observed in the leaves and apical buds of the pBI121transformed coffee plants used as a positive control (Supplementary Fig. S3). In contrast, and whatever the abiotic stress conditions applied, GUS activity was not detected in pBI101-transformed coffee plants (negative control) as well as in roots of the three $C C D R E B 1 D$ promoter haplotypes (Supplementary Table S1).

\section{- Low relative humidity}

Faint GUS staining was observed around the secondary veins of leaves of pHP15L- (Fig. 4 A1) and pHP16L-transformed coffee plants (Fig. 4 A3) subjected to LH conditions. Under higher magnification, several GUS-stained guard cells were also seen in the leaves of these two transgenic lines (Fig. 4 A7 and A9). However, GUS activities were not detected in the leaves of pHP17L-transformed coffee plants (Figs. 4 A5 and A11). In apical buds, GUS staining was stronger in pHP16Ltransformed plants (Fig. 4 A4 and A10) than in those of plants transformed by pHP15L (Fig. 4 A2 and A8). However, no GUS staining was observed in apical buds of pHP17L-transformed plants (Fig. 4 A6 and A12).

\section{- Cold stress}

No GUS staining was observed in the leaves of plants transformed by pHP15L (Fig. 4 B1 and B7) and pHP16L (Fig. 4 B3 and B9) subjected to a low temperature. Conversely, weak GUS activity was observed in the leaves of pHP17L-transformed coffee plants (Fig. 4 B5 and B11). Faint GUS staining was observed in the apical buds of plants transformed by pHP15L (Fig. 4 B2 and B8) and pHP17L (Fig. 4 B6 and B12), while moderate GUS staining was noticed in pHP16L-transformed plants (Fig. 4 B4 and B10).

\section{- Heat stress}

Whatever the CCDREB1D promoter haplotype, no GUS expression was seen in either the leaves (Fig. $4 \mathrm{C} 1, \mathrm{C} 3, \mathrm{C} 5$, $\mathrm{C} 7, \mathrm{C} 9$ and $\mathrm{C} 11$ ) or the roots of transformed plants subjected to heat stress (Supplementary Table 1). Moderate GUS staining was observed in the apical buds of plants transformed by pHP15L (Fig. 4 C2 and C8) and pHP16L (Fig. $4 \mathrm{C} 4$ and C10). 

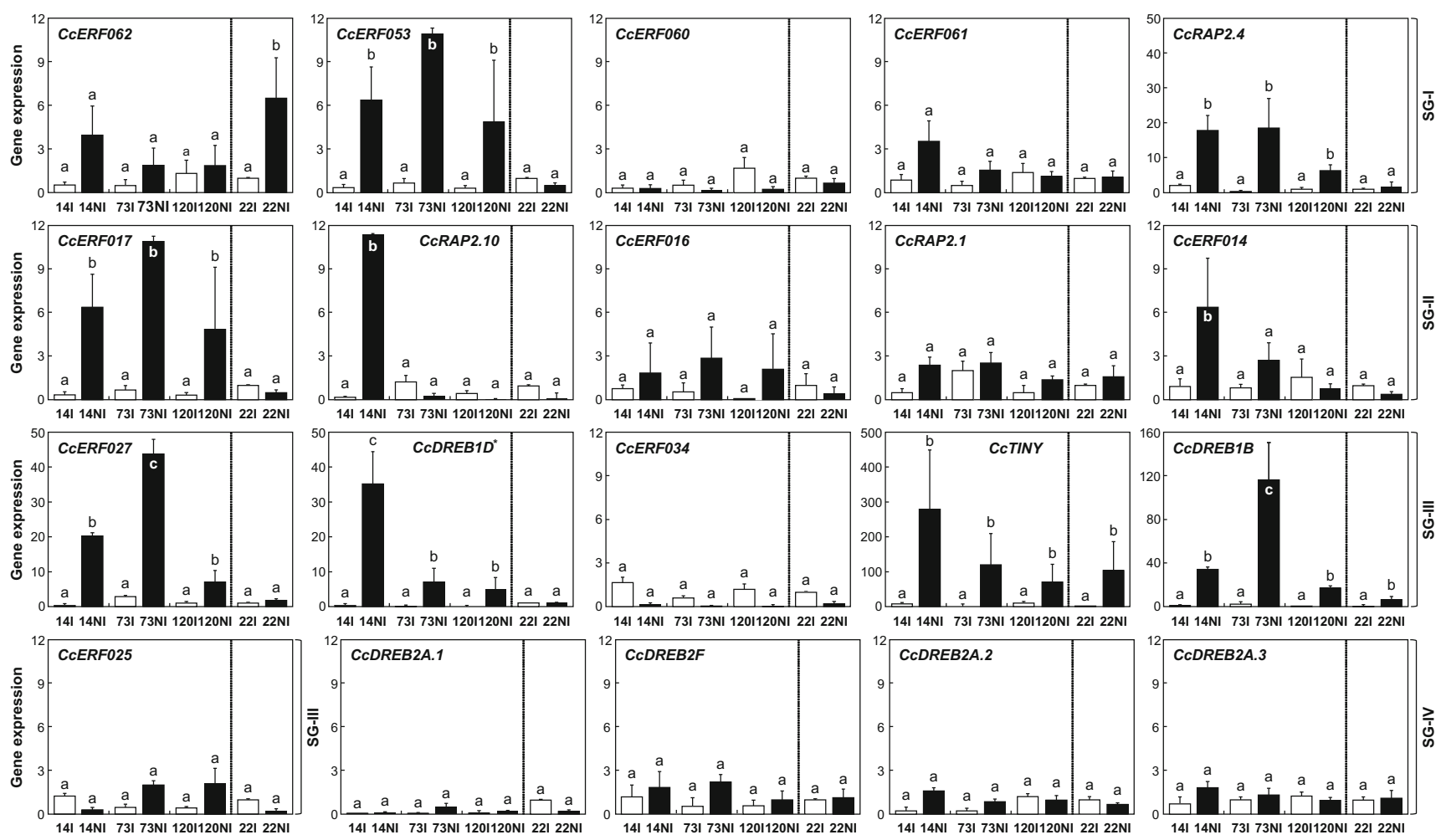

Fig. 2 Expression profiles of $D R E B$-like genes in leaves of $\mathrm{D}^{\mathrm{T}}(14,73$ and 120 ) and $\mathrm{D}^{\mathrm{S}}(22)$ clones of $C$. canephora Conilon subjected to water limitation. I: irrigation (white isobars). NI (not irrigated): water limitation (black isobars). The $\mathrm{D}^{\mathrm{T}}$ and $\mathrm{D}^{\mathrm{S}}$ clones are separated by a vertical dotted line. Gene names are indicated in the histograms. Expression values corresponding to the mean of three biological and technical replications $( \pm \mathrm{SD})$ are expressed in fold change relative to the expression level of the

sample 22I $\left(\mathrm{D}^{\mathrm{S}}\right.$ irrigated $)$ as the reference sample (relative expression $=$ 1). DREB sub-groups (SG) are indicated. Transcript abundances were normalized using the expression of the $C c U B Q 10$ gene as the endogenous control. $\left(^{*}\right)$ : the $C C D R E B 1 D$ expression profile, already published by Marraccini et al. (2012) and Vieira et al. (2013), is shown in order to be compared with expression profiles of other genes. Treatments sharing the same letter are not significantly different

Compared to these haplotype responses, higher GUS staining was detected in the apical buds of pHP17L-transformed plants (Fig. 4 C6 and C12).

\section{- $A B A$ assay}

After $24 \mathrm{~h}$ of ABA treatment, faint GUS staining was systematically observed in the leaves of coffee plants transformed by pHP15L (Fig. 4 D1 and D7), pHP16L (Fig. 4 D3 and D9) and pHP17L (Fig. 4 D5 and D11). GUS staining was considered as weak, medium and strong in the apical buds of plants transformed by pHP15L (Fig. 4 D2 and D8), pHP16L (Fig. 4 D4 and D10) and pHP17L (Fig. 4 D6 and D12), respectively. Strong GUS staining was also observed in the roots of pHP15L-transformed plants (Fig. 5a and b), whereas no GUS activity was detected in the roots of plants transformed by the pHP16L and pHP17L constructions (Supplementary Fig. S3 and Supplementary Table 1). After $48 \mathrm{~h}$ of ABA treatment, GUS staining was considered as weak in the leaves of pHP16L-transformed plants (Fig. 4 E3 and E9) and as moderate in the leaves of pHP15L-transformed plants (Fig. 4 E1 and E7). In the apical buds, moderate and strong GUS activity was observed in plants transformed by pHP15L (Fig. 4 E2 and
E8) and pHP16L (Fig. 4 E4 and E10), respectively. However, no GUS staining was detected in the pHP17L-transformed plants (Fig. 4 E5, E6, E11 and E12).

\section{- High light stress}

Under high light (HL) conditions, intense GUS staining was observed in apical buds, particularly in plants transformed by pHP16L (Fig. 4 F4 and F10) and pHP17L (Fig. 4 F6 and F12) and to a lesser extent, in those transformed by pHP15L (Fig. 4 F2 and F8). Weak GUS staining was also observed in leaves of plants transformed by pHP15L (Fig. $4 \mathrm{~F} 1$ and F7) and pHP17L (Fig. 4 F5 and F11), whereas no GUS activity was observed in the leaves of pHP16L-transformed plants (Fig. 4 F3 and F9).

\section{Proportion of GUS-Stained Guard Cells in Leaves of $C$. arabica Subjected to Different Types of Abiotic Stress}

In order to assess how $C C D R E B 1 D$ promoter haplotypes were regulated, the activity of these sequences was evaluated by 

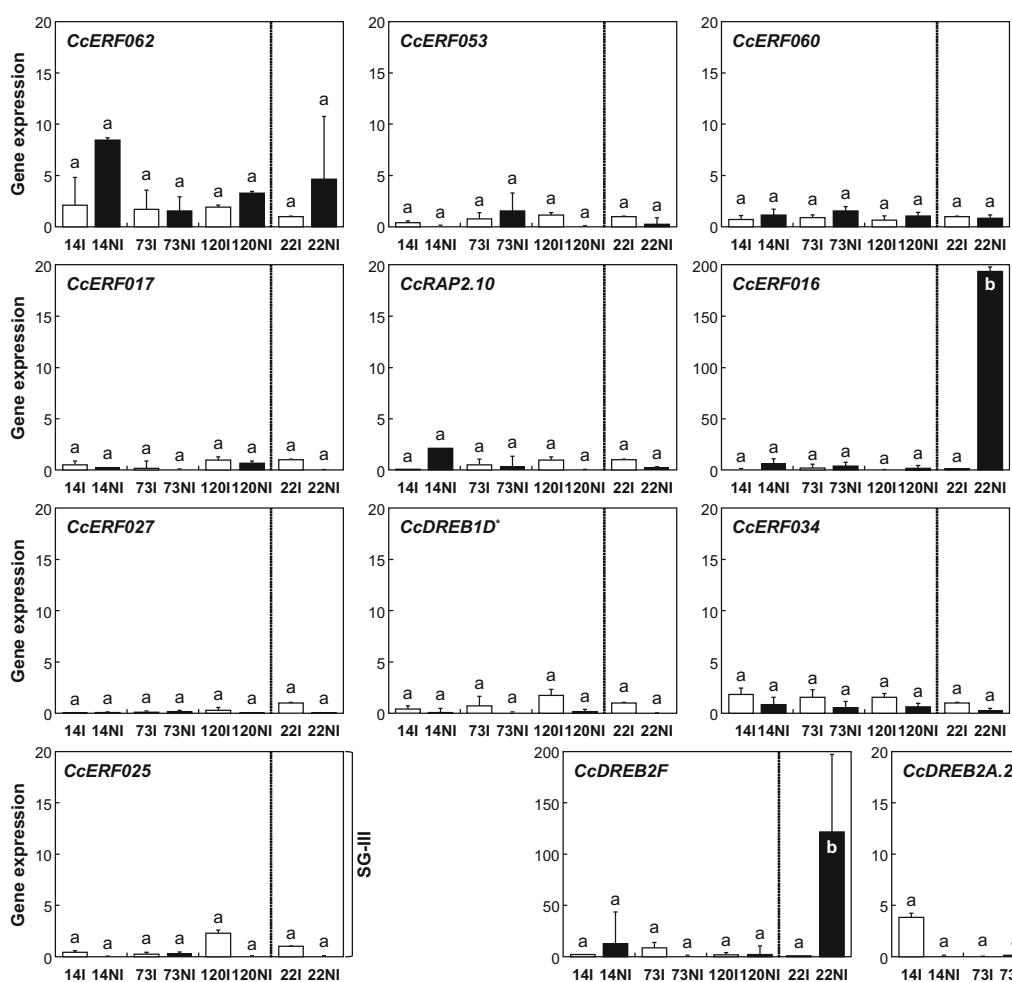

14 I 14NI 73 I 73NI 120I120NI 22I 22NI

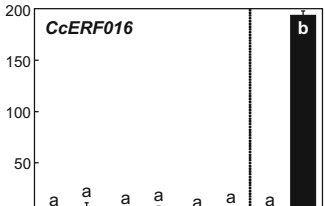

14I 14NI 73I 73NI 1201120NI 22I 22NI
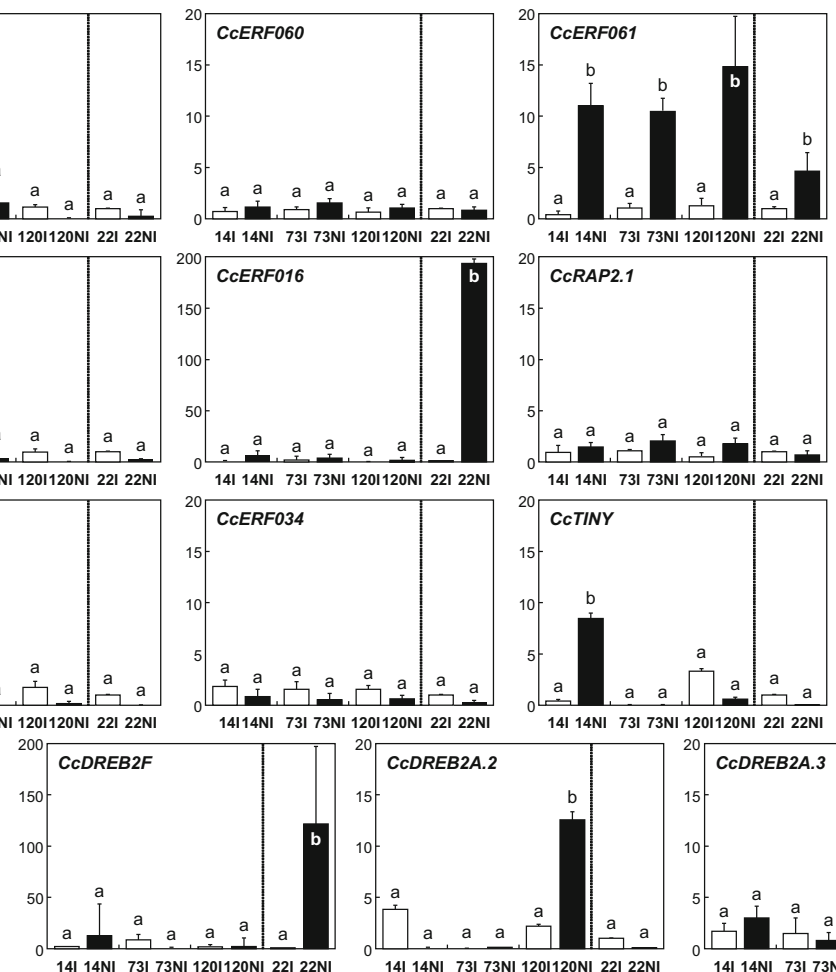

$14 I 14 \mathrm{NI} 73$ I $73 \mathrm{NI} 1201120 \mathrm{NI} 22122 \mathrm{NI}$
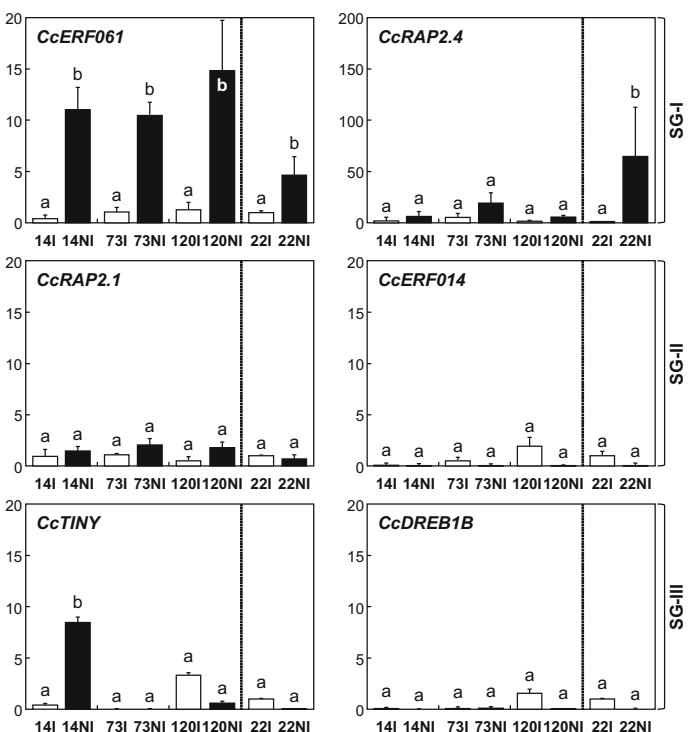

$73173 \mathrm{NI} 1201120 \mathrm{NI} 22122 \mathrm{NI}$

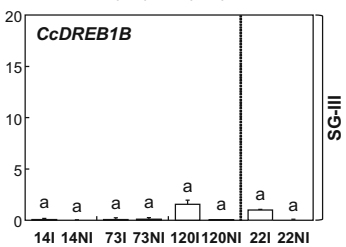

Fig. 3 Expression profiles of $D R E B$-like genes in roots of $\mathrm{D}^{\mathrm{T}}(14,73$ and $120)$ and $D^{S}$ (22) clones of $C$. canephora Conilon subjected to water limitation. I: irrigation (white isobars). NI (not irrigated): water limitation (black isobars). The legend corresponds to that described in

analysing the proportion of GUS-stained guard cells in the leaf abaxial regions of pHP-transformed coffee plants subjected to different types of abiotic stress. As expected, a large proportion of GUS-stained guard cells was observed in the leaves of pBI121-transformed coffee plants (positive control), for example under LH condition (Fig. 6a) but also under all other abiotic stress tested and stress-free conditions (Supplementary Fig. S3). On the other hand, no GUS-stained guard cells were observed in pBI101-transformed plants, in untransformed (WT) coffee plants subjected to LH conditions (negative controls, Fig. $6 \mathrm{~b}$ and c), as well as in pHP-transformed plants under stress-free conditions (Supplementary Table S1).

However, GUS-stained guard cells were observed in the leaves of coffee plants transformed by pHP15L (Fig. 6d) and pHP16L (Fig. 6e) subjected to LH as well as in those of pHP16L-transformed plants subjected to 48-h ABA (Fig. 6f) treatments, for example. In pHP16L-transformed plants, the proportion of GUS-stained guard cells was higher under LH than under ABA treatments. In addition, the proportion of GUS-stained guard cells under LH was also higher in pHP16L- than in pHP15L-transformed plants. Photographs of blue-stained guard cells observed for the cold (Fig. $6 \mathrm{~g}$ ) and high light (Fig. 6h) treatments in pHP17L-transformed plants are also provided as examples of observed GUS staining.

The proportions of GUS-stained guard cells were then measured for each construction and stress condition
Fig. 2. $\left(^{*}\right)$ : the $C c D R E B 1 D$ expression profile, already published by Alves et al. (2018), is shown in order to be compared with expression profiles of other genes. Treatments sharing the same letter are not significantly different

(Fig. 7). The highest proportion of GUS-stained guard cells was observed in pHP16L-transformed plants, particularly for the low humidity ( $\pm 47 \%$ ), and 24 and $48 \mathrm{~h} \mathrm{ABA}$ treatments $( \pm 20 \%)$, but also to a lesser extent for the high light and cold treatments $(<7 \%)$. In pHP17L-transformed plants, the largest proportions of GUS-stained guard cells were observed for the cold (13\%) and high light (8\%) treatments. On the other hand, and whatever the stress conditions, the proportion of GUS-stained cells was always relatively low $(<6 \%)$ in pHP15L-transformed plants. As a positive control, the proportion of GUS-stained guard cells was always large (> 80\%) in pBI121-transformed plants, whereas no GUS-stained guard cells were detected in pBI101-transformed plants.

Fig. 4 Histochemical location of GUS activity in transgenic plants of C. arabica var. Caturra transformed independently by CCDREBID promoter haplotype constructions, called pHP15L, pHP16L and pHP17L, and subjected to low humidity (A), cold (B), heat (C), ABA (D, $24 \mathrm{~h}$; E, 48 h), and high light (E) stress treatments. For each construction and stress condition, GUS staining of leaves (even numbers) and apical buds (odd numbers) was analysed by a binocular loupe (1-6, with bar scales of $3.0 \mathrm{~mm}$ for leaves and $1.5 \mathrm{~mm}$ for apical buds) and by bright field microscopy of longitudinal- or cross-sections of the organs (7-12, with bar scales of $80 \mu \mathrm{m}$ for leaves and $300 \mu \mathrm{m}$ for apical buds). These images correspond to the most representative patterns of GUS staining observed for each pHP construction 


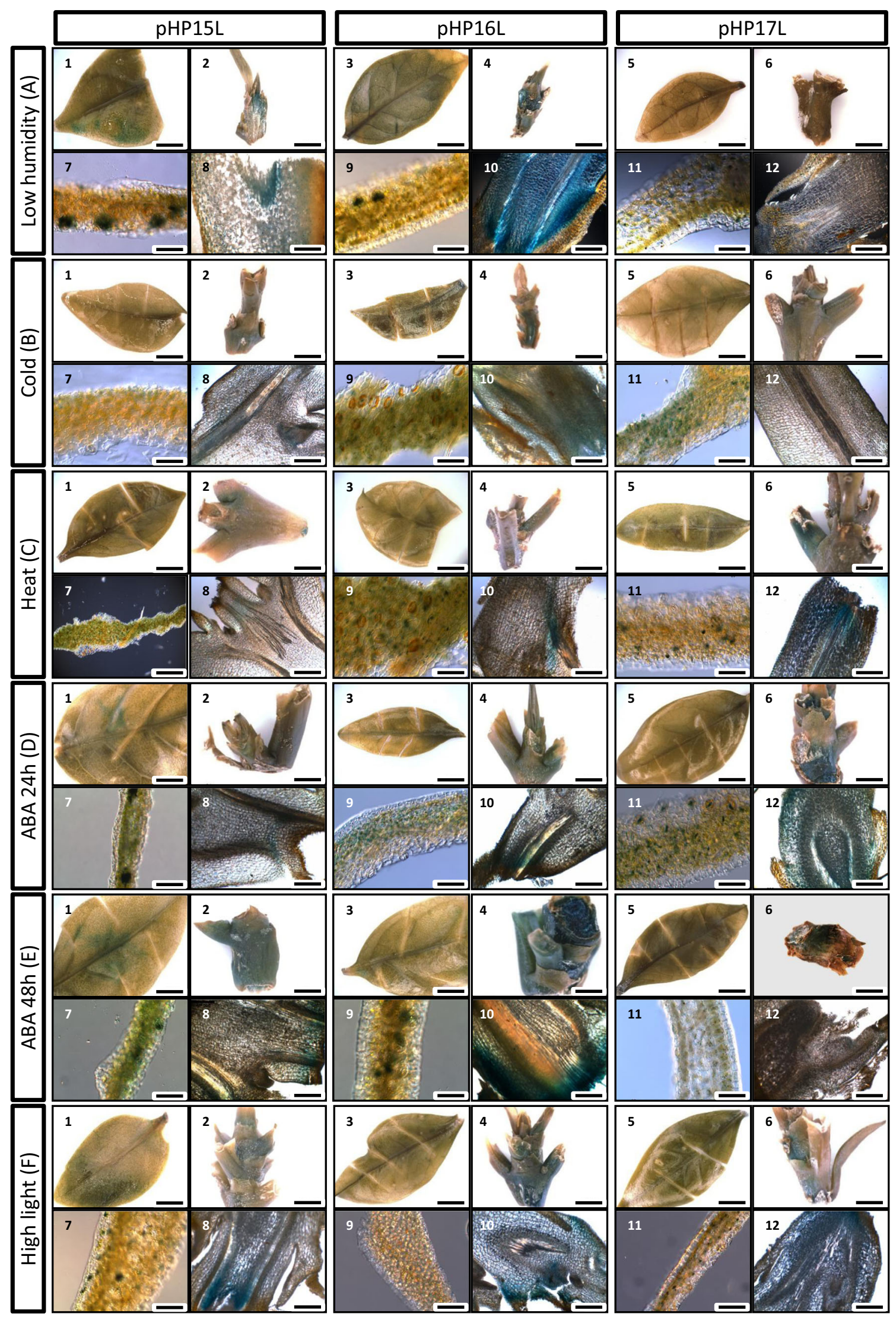




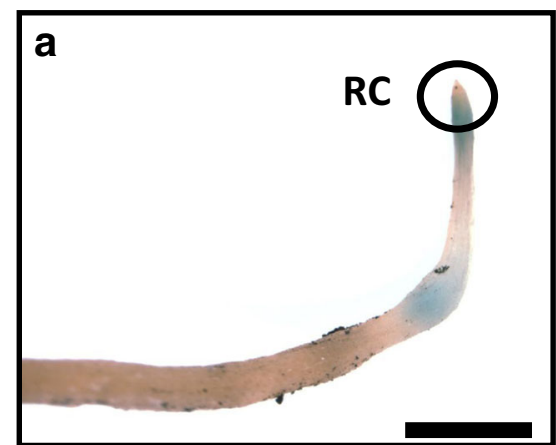

Fig. 5 Histochemical location of GUS activity in roots of $C$. arabica plants transformed by the $C c D R E B 1 D$ promoter haplotype $\mathrm{pHP} 15 \mathrm{~L}$ and subjected to the ABA for a period of $24 \mathrm{~h}$. a Binocular loupe image (bar =

\section{Expression of uidA and Endogenous CaDREB1D Genes}

Since the largest proportions of GUS-stained guard cells were observed in pHP16L-transformed plants, these plants were

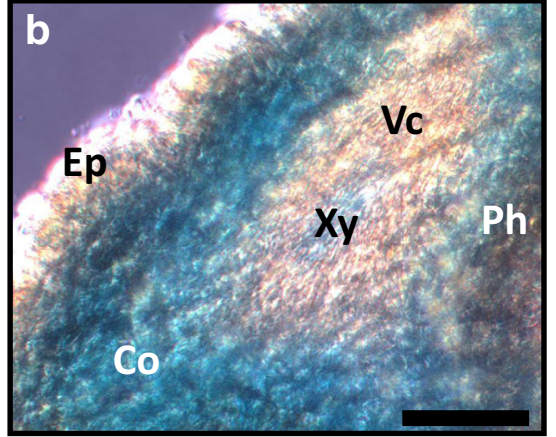

$1.5 \mathrm{~mm}$ ). $\mathbf{b}$ Bright field microscopy of root tissues in cross-section (bar = $40 \mu \mathrm{m})$. Tissue abbreviations: Rc: root cap; Ep: epidermis; Co: cortex; Xy: xylem; Ph: phloem; Vc: vascular cylinder

used to check expression in the leaves of the uidA reporter gene and $C a D R E B 1 D$ endogenous gene for the cold (LT), heat (HT), low humidity (LH), high light (HL) and 24-h ABA treatments by RT-qPCR experiments (Fig. 8). Under stressfree (NS) conditions, uidA and CaDREB1D transcripts were
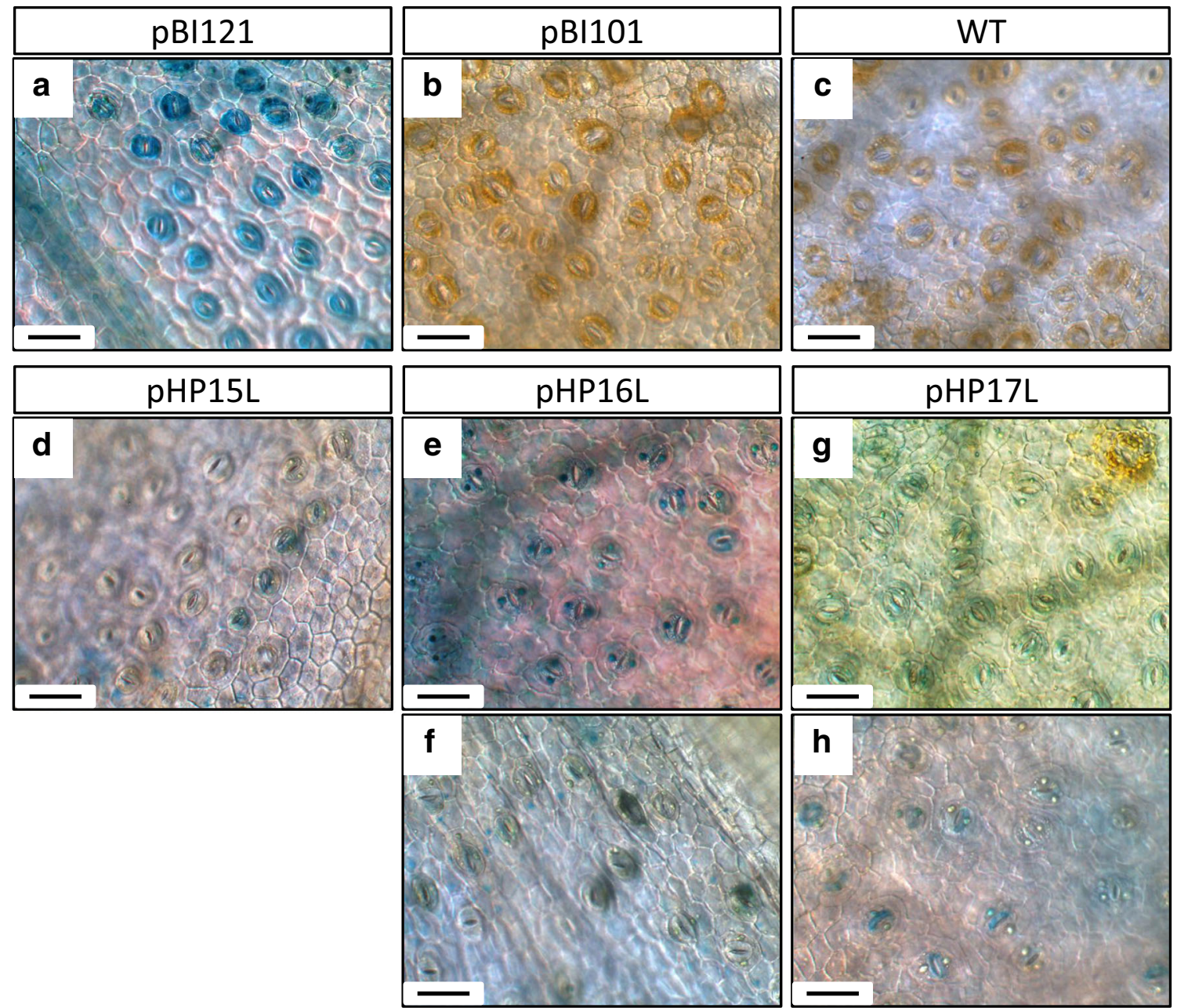

Fig. 6 Examples of GUS staining observed in guard cells of $C$. arabica plants transformed by the CCDREB1D promoter haplotype (pHP) and subjected to abiotic stresses. Stomata were visualized by bright field microscopy in the abaxial region of leaves of untransformed (WT = wild type) coffee plants and in those of plants transformed by pBI101 (negative control), pBI121 (positive control), pHP15L and pHP16L, pHP17L subjected to low humidity (a, b, c, d and e), $48 \mathrm{~h}$ ABA (f), cold (g) and high light (h) treatments. Bars represent $80 \mu \mathrm{m}$ 


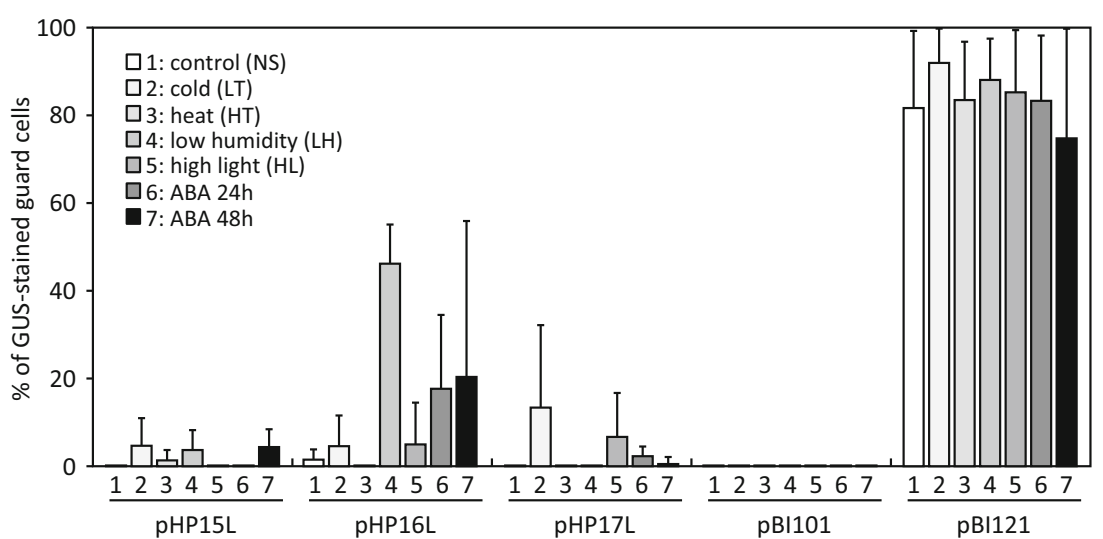

Fig. 7 Proportion of GUS-stained guard cells in leaves of $C$. arabica plants transformed by the $C C D R E B 1 D$ promoter haplotype (pHP) subjected to different types of abiotic stress. The colours used for each type of abiotic stress (cold, heat, low humidity, high light and ABA $24 \mathrm{~h} /$

barely detected. Conversely, the transcripts of these two genes were highly accumulated with the LT and LH treatments, and to a lesser extent under heat stress (HT). Compared to these conditions, a low but significant increase in transcript levels was also detected for uidA and CaDREB1D under high light (HL) and for uidA under ABA treatment.

\section{Discussion}

\section{Expression of DREB-Like Genes in C. arabica and $C$. canephora}

Whatever the primer pairs, or the tissues and conditions tested during this study, the results presented here did not enable us to detect expression of the ERF013, DREB1C, ERF023, ERF024,
$48 \mathrm{~h}$ ) are defined in the fig. NS corresponds to the control (no stress). The proportions of GUS-stained guard cells in pBI121- and pBI101transformed coffee plants were used as positive and negative controls, respectively
DREB3, ERF039, ABI4, DREB2G and DREB2D genes in the $C$. arabica and $C$. canephora species by RT-qPCR. The fact that coffee ESTs with similarity to ERF013 and ERF024 were not present in the public nucleic databases suggests that these genes correspond to pseudogenes (never expressed) or to genes expressed in very specific conditions or tissues, not studied in previous coffee cDNA library sequencing projects (Lashermes et al. 2008; Vieira et al. 2006; Mondego et al. 2011). Dussert et al. (2018) recently reported $C a A B I 4$ gene expression in the embryos during the latest stages of coffee bean development therefore indicating that this gene is functional. This also seems to be the case for the ERF016 and ERF062 genes which were weakly up-regulated by abiotic stress in the leaves of C. arabica and by drought in the leaves of C. canephora.

A different situation was observed for the ERF023, $D R E B 3, E R F 039, D R E B 2 G$ and $D R E B 2 D$ genes, for which

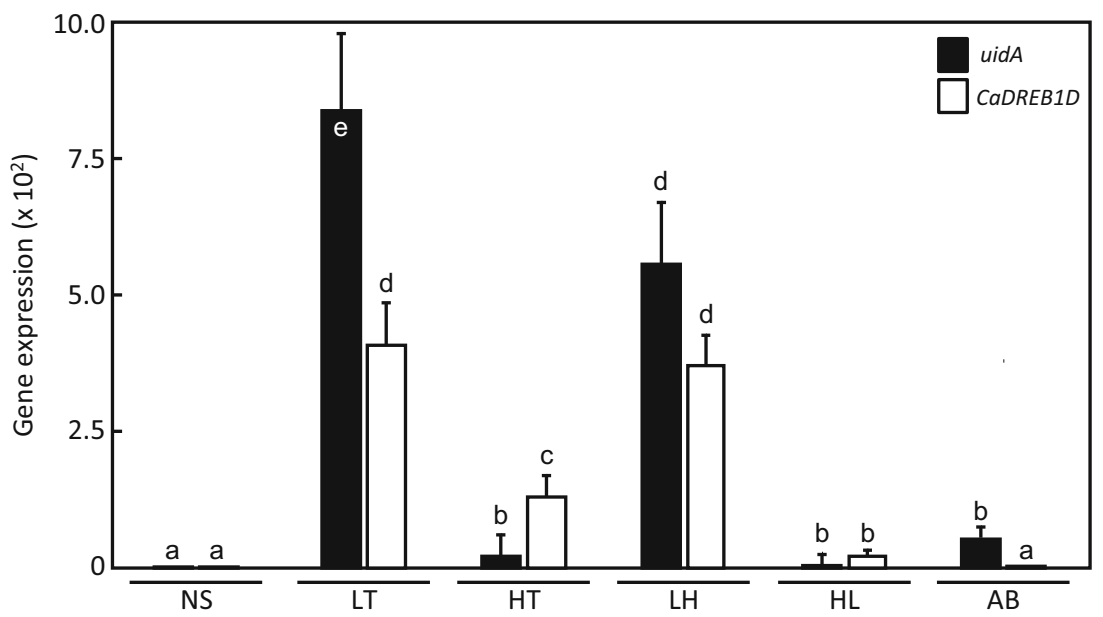

Fig. 8 Expression profiles of the uidA and CaDREB1D genes in leaves of C. arabica var. Caturra plants transformed by $\mathrm{pHP} 16 \mathrm{~L}$ subjected to low (LT) and high (HT) temperatures, low humidity (LH), ABA (AB) and high light (HL) conditions. Expression was analysed by RT-qPCR using the GUS-F/R and DREBA09-F/R primer pairs (Table 2) for the uidA (black isobars) and CaDREBID (white isobars) genes, respectively.
Expression values corresponding to the mean of three biological and technical replications $( \pm \mathrm{SD})$ are expressed in fold change relative to the expression level of NS (control, no stress) sample used as the reference sample (relative expression $=1$ ). Transcript abundances were normalized using the expression of the $C c U B Q 10$ gene as the endogenous control. Treatments sharing the same letter are not significantly different 
ESTs displaying high sequence similarity were found in different coffee cDNA libraries (e.g. from fruits and leaves). In a recent study, the expression of $D R E B 2 G$ gene was reported to be highly up-regulated in the endosperm during the DT (desiccation tolerance) phase occurring at the end of C. arabica bean development (Dussert et al. 2018). If we consider that all the primer pairs tested for these genes were appropriate (in terms of specificity and efficiency), we concluded that these five genes were not expressed under the different conditions tested in our study.

For the remaining twenty-two genes, sixteen were expressed in both coffee species, four (ERF061, DREB1B, $E R F 025$ and $D R E B 2 F$ ) were expressed in $C$. canephora but not in $C$. arabica and two (ERF043 and DREB2C) were expressed in C. arabica but not in C. canephora. The limited number of corresponding ESTs to these genes found in the cDNA libraries of C. arabica (Vieira et al. 2006; Mondego et al. 2011) and C. canephora (Lin et al. 2005; Poncet et al. 2006) demonstrates their low expression and probably explains the difficulty in detecting their transcripts.

The fact that some genes were expressed in one species but not in the other, could also reflect the occurrence of different regulations of their homeologs (Vidal et al. 2010; Marraccini et al. 2011). Indeed, all primers used in this study were deduced from the C. canephora genome sequence. However, C. arabica is an amphidiploid species (originating from a cross between C. canephora and C. eugenioides) and its transcriptome is a mixture of genes expressed from both $\mathrm{C}$. eugenioides $(\mathrm{CaCe})$ and C. canephora $(\mathrm{CaCc})$ sub-genomes (Vidal et al. 2010). In this context, it is possible that the primers used in this study recognized only the $D R E B$-like genes of $C a C c$ subgenome and not those of $\mathrm{CaCe}$. The access to the C. arabica genome sequence (Mueller et al. 2015) should solve this point through the design of primers able to analyze the expression of each homeologs.

The absence of gene expression in one species, but not the other, might also be explained by the fact that plant growth and drought stress conditions were not similar between $C$. arabica and $C$. canephora. Indeed, the $C$. arabica plants were cultivated in vitro and subjected for $12 \mathrm{~h}$ to low RH (Alves et al. 2017), while $C$. canephora clones were grown under greenhouse conditions with water withdrawal for several days before being stressed (Marraccini et al. 2011, 2012). Under these conditions, the expression profiles of $D R E B$-like genes presented here for $C$. arabica and $C$. canephora could be considered as rapid and late responses, respectively. Several authors have already reported rapid expression (within a few hours) of DREB-like genes under drought (Sun et al. 2008; Wang et al. 2008; Li et al. 2011). More recently, Thioune et al. (2017) reported a peak of CCDREBID transcripts after only $45 \mathrm{~min}$, followed by a decrease, in $C$. canephora leaves subjected simultaneously to a $30 \% \mathrm{RH}$ and heat shock $\left(35^{\circ} \mathrm{C}\right)$, characterizing a fast and transient expression of this gene. On the other hand, the expression of DREB genes over longer periods (from $24 \mathrm{~h}$ up to several days) of drought was also reported in maize (Liu et al. 2013), Pisum sativum (Jovanović et al. 2013), Brassica oleracea (Li et al. 2017) and grape (Zandkarimi et al. 2015), for example.

\section{DREB-Like Genes Are Differentially Expressed in $C$. arabica under Abiotic Stress}

Differential expression of DREB genes under various types of abiotic stress has already been reported in many plants (Lata and Prasad 2011). In Arabidopsis, expression of DREB1A/ $C B F 3, D R E B 1 B / C B F 1$ and $D R E B 1 C / C B F 2$ was up-regulated by cold (Gilmour et al. 1998), while $D R E B 2 A$ responded to drought, salt and ABA (Liu et al. 1998), DREB2C responded to salt, mannitol and cold (Lee et al. 2010) and DREB1D/CBF4 responded to drought and ABA (Haake et al. 2002). The gene expression profiles presented here in leaves of $C$. arabica showed that the CaERF017, CaDREBID and CaTINY genes were highly up-regulated by both cold and low humidity. The expression of CaERF053, CaRAP2.4, CaERF027 and CaDREB2A.1 was also up-regulated specifically by low humidity. Of all the genes tested, CaERF014 was the unique gene up-regulated only by high temperature.

\section{DREB-Like Genes Are Differentially Expressed in Leaves and Roots of $D^{\top}$ and $D^{S} C$. canephora Clones Subjected to Water Limitation}

In C. canephora, it is worth noting that gene expression levels in leaves under WL conditions were always higher in $\mathrm{D}^{\mathrm{T}}$ clones than in $\mathrm{D}^{\mathrm{S}}$ clone 22. This was particularly the case of CcERF053, CcRAP2.4, CcERF017, CcERF027 and $C C D R E B 1 D$ which were over-expressed under $\mathrm{WL}$ in $\mathrm{D}^{\mathrm{T}}$ but not in the $\mathrm{D}^{\mathrm{S}}$ clones. Some differences in expression levels were also observed between $\mathrm{D}^{\mathrm{T}}$ clones. For example, leaf expression of $C C E R F 027$ and $C C D R E B 1 B$ under WL was greater in $\mathrm{D}^{\mathrm{T}}$ clone 73 than in $\mathrm{D}^{\mathrm{T}}$ clones 14 and 120 . On the other hand, expression of $C c R A P 2.10$ and $C C D R E B 1 D$ was significantly greater in $\mathrm{D}^{\mathrm{T}}$ clone 14 than in $\mathrm{D}^{\mathrm{T}}$ clones 73 and 120.

In roots, WL up-regulated the expression of CCERF061 (mainly in $\mathrm{D}^{\mathrm{T}}$ clones), CCTINY (in $\mathrm{D}^{\mathrm{T}}$ clone 14) and CCDREB2A.2 (in $\mathrm{D}^{\mathrm{T}}$ clone 120). More interestingly, expression of the CCRAP2.4, CcERF016 and CCDREB2F genes was highly induced under WL conditions, specifically in roots of $\mathrm{D}^{\mathrm{S}}$ clone 22. In these cases, gene expression levels were among the highest measured in roots and opposite to those observed in leaves, where they were very low. These results back the idea that roots are key organs in the adaptation of coffee plants to water deficit (Pinheiro et al. 2005). These results confirmed those previously reported in $C$. canephora showing the existence of different mechanisms among the $\mathrm{D}^{\mathrm{T}}$ clones of 
C. canephora as regards water deficits (Marraccini et al. 2012; Vieira et al. 2013). They also highlighted the differential expression of $D R E B$-like genes occurring in leaves and roots of $\mathrm{D}^{\mathrm{T}}$ and $\mathrm{D}^{\mathrm{S}}$ coffee clones. Similar results were already described when comparing leaf and root expression profiles in $\mathrm{D}^{\mathrm{T}}$ and $\mathrm{D}^{\mathrm{S}}$ varieties of Vitis vinifera (Zandkarimi et al. 2015) and lines of Zea mays L. (Zhang et al. 2017), for DREB/CBF and ERF encoding genes, respectively. Cohen et al. (2010) also reported high up-regulation of several orthologues of dehydrationresponsive-element binding protein such as $D R E B 2 A$, DREB1A and DREB1D in roots of Populus deltoides subjected to drought. Altogether, these results clearly suggest that the specific up-regulation of these $D R E B$ genes in response to WL, particularly in the roots of these plants, might participate in enhancing their response and/or adaptation to limited soil water content (Joshi et al. 2016).

\section{CCDREB1 Promoter Haplotypes Are Differentially Regulated in Leaves of $C$. arabica Subjected to Different Types of Abiotic Stress}

Among the genes involved in plant responses to stress, the expression of many of them was shown to be under the control of DREB transcription factors (Lata and Prasad 2011). Despite the importance of these genes, a limited number of $D R E B$ promoters have been analysed using transgenic approaches. We recently reported the differential expression of three $C C D R E B 1 D$ promoter haplotypes under water deficit in transgenic coffee plants (Alves et al. 2017). these promoter haplotypes through their capacity to control the expression of the uidA reporter gene in transgenic plants of $C$. arabica subjected to other abiotic stress.

The GUS staining results presented here showed that the HP15, HP16 and HP17 haplotypes of the CCDREB1D promoter did not function in the leaves, apical buds and roots of unstressed coffee plants. However, blue-stained tissues were detected in transgenic coffee plants transformed by all haplotypes when those plants were subjected to low humidity, cold, heat, high light and ABA treatments. For example, strong GUS staining was observed in the roots of pHP15Ltransformed coffee plants under $24 \mathrm{~h}$ of ABA treatment, but also in the apical buds of pHP16L-transformed plants subjected to $48 \mathrm{~h}$ ABA and low humidity, as well as in those of pHP17L-transformed plants subjected to $24 \mathrm{~h} \mathrm{ABA}$, heat and high light treatments. These results are similar to those already reported for promoters AtDREB1C (Zarka et al. 2003), $A t D R E B 2 C$ (Chen et al. 2012), OsDREB1B (Gutha and Reddy 2008), GmDREB3 (Chen et al. 2009) and FeDREB1 (Fang et al. 2015) showing that proximal regions (up to $1.3 \mathrm{~kb}$ ) harboured all the cis-regulatory elements (CREs) required to correctly regulate the expression of the uidA reporter gene in transgenic plants. Moreover, the fact that high accumulation of the uidA transcripts in pHP16L-transformed plants subjected to cold and low humidity overlapped the increase of $C a D R E B 1 D$ endogenous transcripts also indicated that the transcriptional machinery of allotetraploid $C$. arabica correctly regulated the HP16 haplotype of $C C D R E B 1 D$ promoter from the diploid $C$. canephora.

The GUS staining results presented here also emphasized the fact that the HP15, HP16 and HP17 haplotypes responded in different ways to the same abiotic treatments. For example, the proportion of GUS-stained guard cells was larger in pHP16L-transformed plants subjected to LH and exogenous ABA (after both $24 \mathrm{~h}$ and $48 \mathrm{~h}$ of treatment), than the proportion measured in plants transformed by pHP15L and pHP17L and subjected to the same stress. These results are similar to those previously reported in the same plants by Alves et al. (2017) showing a larger proportion of GUS-stained guard cells in pHP16L-transformed plants than in coffee transformed by $\mathrm{pHP} 15 \mathrm{~L}$ and $\mathrm{pHP} 17 \mathrm{~L}$ subjected to low humidity mimicked by PEG treatment.

The increased proportion of GUS-stained guard cells observed in pHP16L-transformed coffee plants subjected to abiotic stress was confirmed by analysing expression of the uidA reporter gene. In that case, the amount of uidA transcripts increased under cold and low humidity, as well as (but to a lesser extent) under $24 \mathrm{~h}$ of ABA. Our results also showed that the uidA transcripts were not detected after $3 \mathrm{~h}$ of heat and high light treatment in pHP16L-transformed plants, thereby confirming the small proportion (and even the absence) of GUS-stained guard cells for these treatments. However, the low uidA gene expression observed after $3 \mathrm{~h}$ of ABA treatment did not match the relatively high proportion of GUSstained stomata observed after $24 \mathrm{~h}$ and $48 \mathrm{~h}$ of ABA treatment. The up-regulated expression of the uidA occurring after $3 \mathrm{~h}$ of ABA treatment could explain this situation. In that sense, it is worth noting that Arabidopsis genes containing the DREB1A/CBF3 motif in their promoters were mainly upregulated after $6 \mathrm{~h}$ of ABA treatment (Huang et al. 2007).

Several guard cell-specific genes have already been reported (Wang et al. 2011; Virlouvet and Fromm 2015). Interestingly, the guard cell transcriptome is particularly rich in transcription factor-encoding genes including DREB, WRKY, MYB and MYC (Hachez et al. 2011; Baldoni et al. 2015). In the great majority, functional analyses of their promoters have shown that expression was not restricted to guard cells, but was in fact guard cell-preferred, with expression often observed in mesophyll cells, as well as in leaf veins and trichomes, for example (Han et al. 2013). However, guard cell-exclusive expression was reported in Arabidopsis promoters of CYP86A2 and MYB60 genes (Galbiati et al. 2008; Yang et al. 2008; Cominelli et al. 2011). In addition to its guard cell specificity, the activity of the AtMYB60 promoter, but also of the $V v M Y B 60$ promoter from Vitis vinifera, was also shown to be rapidly down-regulated by ABA (Galbiati et al. 2011; 
Rusconi et al. 2013). Computational analyses have also shown that the G-box containing the classical ABAregulated elements (ABRE) was overrepresented in guard cell-specific promoters that were ABA-upregulated (Leonhardt et al. 2004; Wang et al. 2011). Interestingly, in their long (L) versions, the HP15, HP16 and HP17 CCDREB1D promoter haplotypes all contained several ABRE-like motifs (Alves et al. 2017).

To our knowledge, the results presented here are the first demonstrating guard cell up-regulated expression of a $D R E B 1 D$ promoter in response mainly to $\mathrm{ABA}$ and low humidity in coffee plants. However, cold, heat shock and high light treatments were less efficient in up-regulating the expression of this haplotype. The fact that DREB genes responded in different ways to abiotic stress was already reported in the literature. For example, the expression of AtDREB1D (also known as $A t C B F 4$ ) was up-regulated by drought but not by cold in Arabidopsis (Haake et al. 2002). However, cold and drought treatments up-regulated the expression of DREB1D in Vitis sp. (Xiao et al. 2008; Zandkarimi et al. 2015) and Medicago truncatula (Li et al. 2011).

Studies demonstrating differential expression of haplotypes (or alleles) of the same promoter are also very limited in plants (de de Meaux et al. 2005; Takeshima et al. 2016). In the present work, the comparison of GUS staining in stomata guard cells, leaves, roots and apical buds, clearly demonstrated that the three $C C D R E B 1 D$ promoter haplotypes responded differentially to abiotic stress. Since the HP16 haplotype was isolated from C. canephora $\mathrm{D}^{\mathrm{T}}$ clone 14 , this might explain why CCDREB1D gene expression was highly up-regulated by WL in the leaves of this clone, but not in those of $\mathrm{D}^{\mathrm{S}}$ clone 22 harbouring the HP15 and HP17 haplotypes (Marraccini et al. 2012).

In roots, water deficiency up-regulated the expression of DREB1 genes in pine (Lorenz et al. 2011), soybean (Ha et al. 2015) and poplar (Cohen et al. 2010). The fact that a higher rootto-shoot ratio was observed in transgenic plants overexpressing $D R E B$ genes also demonstrates the key role of these genes in root system development (Janiak et al. 2016). Interestingly, Pinheiro et al. (2005) showed that C. canephora $\mathrm{D}^{\mathrm{T}}$ clone 14 had deeper roots than $\mathrm{D}^{\mathrm{S}}$ clones, suggesting that root architecture contributes to drought tolerance in coffee. Even though expression of $C C D R E B 1 D$ was barely detected in the roots of C. canephora $\mathrm{D}^{\mathrm{S}}$ and $\mathrm{D}^{\mathrm{T}}$ clones subjected to $\mathrm{WL}$, the results presented here clearly showed ABA-induced GUS staining in the roots of pH15L-transformed plants. In addition to the peak of CCDREB1D transcripts observed in leaves C. canephora subjected to a humidity shock treatment, Thioune et al. (2017) also reported concomitant expression of $C C N C E D 3$ (encoding a protein involved in ABA synthesis) and CCATAF1 (encoding a putative protein ortholog of AtATAF1 from Arabidopsis known to regulate AtNCED3 promoter activity). The expression of the first gene was already reported to be induced by drought in leaves of C. arabica (Simkin et al. 2008) but also in roots of
C. canephora (Costa 2014). Altogether, the results presented here highlight the capacity of $C C D R E B 1 D$ promoter haplotypes in regulating (in different ways) the expression of the $u i d A$ reporter gene in the guard cells of transgenic coffee plants, and suggest a key role of $\mathrm{ABA}$ in controlling $C C D R E B 1 D$ gene expression in response to WL in coffee. They also showed that $D R E B$-like genes reported here to be differentially expressed between clones and/or under different abiotic stress could be used as (positive and/or negative) markers in future breeding programmes aiming to generate new coffee cultivars better adapted to climate change (Bertrand et al. 2016).

Acknowledgments This work was carried out under the project of scientific cooperation between Embrapa and Cirad (2011-2017) entitled "Evaluation of coffee (Coffea arabica and C. canephora) germplasm in conditions of water stress for genetic improvement: innovation and recommendations for adaptation of coffee production in dry areas" and under the CAPES (Coordenação de Aperfeiçoamento de Pessoal de Nível Superior) / COFECUB (Comité Français d'Évaluation de la Coopération Universitaire et Scientifique avec le Brésil) project n ${ }^{\circ}$ 07-2012 (2012-2015) between University of Lavras and Montpellier SupAgro entitled "Genomics and biotechnology applied to the creation of new drought tolerant coffee cultivars". The authors acknowledge UMR-AGAP - CIRAD, Brazilian Consortium on Coffee R\&D, Brazilian Innovation Agency (FINEP), Instituto Nacional de Ciência e Tecnologia do Café/Conselho Nacional de Desenvolvimento Cientifico e Tecnologico (INCT/CNPq), Fundação de Amparo à Pesquisa do Estado de Minas Gerais (FAPEMIG) and CAPES/ COFECUB for financial support. We are also grateful to Peter Biggins (CIRAD) for the English revision of the manuscript. This work was carried out under the International Consortium in Advanced Biology (CIBA: https://www.ciba-network.org/).

Author's Contribution LFT, TR, SOA, KED, TSC, JCB, MGC and TSC extracted RNA samples, performed qPCR experiments and analysed the results. LFT, ED, HE and GSCA carried out genetic transformation, applied abiotic stress on C. arabica and performed GUS staining and microscopy analyses with the help of MC. HE, ACA and PM designed the study, drew up the experimental design and implemented it. LFT, ATS, LECD, LVP, ACA, HE and PM wrote the manuscript. All authors read and approved the final manuscript.

\section{Compliance with Ethical Standards}

Conflict of Interest All authors declare that they have no conflict of interest.

\section{References}

Alves GSC (2015) Characterization of a candidate gene for drought tolerance in Coffea: the CcDREB1D gene, in contrasting genotypes of Coffea canephora and related species. $\mathrm{PhD}$ dissertation, Montpellier SupAgro, France

Alves GSC, Torres LF, Déchamp E, Breitler JC, Joët T, Gatineau F, Andrade AC, Bertrand B, Marraccini P, Etienne H (2017) Differential fine-tuning of gene expression regulation in coffee leaves by $C C D R E B 1 D$ promoter haplotypes under water deficit. $\mathrm{J}$ Exp Bot 68:3017-3031. https://doi.org/10.1093/jxb/erx166

Alves GSC, Torres LF, de Aquino SO, Reichel T, Freire LP, Vieira NG, Vinecky F, This D, Pot D, Etienne H, Paiva LV, Marraccini P, 
Andrade AC (2018) Nucleotide diversity of the coding and promoter regions of $D R E B 1 D$, a candidate gene for drought tolerance in Coffea species. Trop Plant Biol 11:31-48. https://doi.org/10.1007/ s12042-018-9199-x

Andrade AC (2018) Developments in molecular breeding techniques in Robusta coffee. In: Lashermes P (ed) Achieving sustainable cultivation of coffee. Burleigh Dodds, Cambridge, pp 139-158

Atkinson NJ, Urwin PE (2012) The interaction of plant biotic and abiotic stresses: from genes to the field. J Exp Bot 63:3523-3544. https:// doi.org/10.1093/jxb/ers100

Baldoni E, Genga A, Cominelli E (2015) Plant MYB transcription factors: their role in drought response mechanisms. Int J Mol Sci 16: 15811-15851. https://doi.org/10.3390/ijms160715811

Barsalobres-Cavallari CF, Severino FE, Maluf MP, Maia IG (2009) Identification of suitable internal control genes for expression studies in Coffea arabica under different experimental conditions. BMC Mol Biol 10(1):1. https://doi.org/10.1186/1471-2199-10-1

Bertrand B, Marraccini P, Villain L, Breitler JC, Etienne H (2016) Healthy tropical plants to mitigate the impact of climate change as exemplified in coffee. In: Torquebiau E (ed) Climate change and agriculture worldwide. Springer, Heidelberg, pp 83-95

Breitler JC, Campa C, Georget F, Bertrand B, Etienne H (2016) A singlestep method for RNA isolation from tropical crops in the field. Sci Rep 6:38368. https://doi.org/10.1038/srep38368

Bunn C, Läderach P, Pérez Jimenez JG, Montagnon C, Schilling T (2015) Multiclass classification of agro-ecological zones for Arabica coffee: an improved understanding of the impacts of climate change. PLoS ONE 10:e0140490. https://doi.org/10.1371/journal.pone. 0140490

Canella D, Gilmour SJ, Kuhn LA, Thomashow MF (2010) DNA binding by the Arabidopsis CBF1 transcription factor requires the PKKP/RAGRxKFxETRHP signature sequence. Biochim Biophys Acta 1799:454-462. https://doi.org/10.1016/j.bbagrm.2009.11.017

Chen M, Xu Z, Xia L, Li L, Cheng X, Dong J, Wang Q, Ma Y (2009) Cold-induced modulation and functional analyses of the DREbinding transcription factor gene, GmDREB3, in soybean (Glycine $\max$ L.). J Exp Bot 60:121-135. https://doi.org/10.1093/jxb/ern269

Chen H, Je J, Song C, Hwang JE, Lim CO (2012) A proximal promoter region of Arabidopsis $D R E B 2 C$ confers tissue-specific expression under heat stress. J Integr Plant Biol 54:640-651. https://doi.org/10. 1111/j.1744-7909.2012.01137.x

Cohen D, Bogeat-Triboulot MB, Tisserant E, Balzergue S, MartinMagniette ML, Lelandais G, Ningre N, Renou JP, Tamby JP, le Thiec D, Hummel I (2010) Comparative transcriptomics of drought responses in Populus: a meta-analysis of genome-wide expression profiling in mature leaves and root apices across two genotypes. BMC Genomics 11:630. https://doi.org/10.1186/1471-2164-11-630

Cominelli E, Galbiati M, Albertini A, Fornara F, Conti L, Coupland G, Tonelli C (2011) DOF-binding sites additively contribute to guard cell-specificity of AtMYB60 promoter. BMC Plant Biol 11:162. https://doi.org/10.1186/1471-2229-11-162

Costa TS (2014) Análise do perfil transcriptômico e proteômico de raízes de diferentes clones de Coffea canephora em condições de déficit hídrico. PhD dissertation, Federal University of Lavras, Brazil

DaMatta FM, Ramalho JC (2006) Impact of drought and temperature stress on coffee physiology and production: a review. Braz J Plant Physiol 18:55-81. https://doi.org/10.1590/S167704202006000100006

Davis AP, Gole TW, Baena S, Moat J (2012) The impact of climate change on indigenous Arabica coffee (Coffea arabica): predicting future trends and identifying priorities. PLoS ONE 7:e47981. https://doi.org/10.1371/journal.pone.0047981

de Aquino SO, de Araújo Carneiro F, Rêgo ECS, Alves GSC, Andrade AC, Marraccini P (2018) Functional analysis of different promoter haplotypes of the coffee (Coffea canephora) CcDREBID gene through genetic transformation of Nicotiana tabacum. Plant Cell Tissue Organ Cult 132:279-294. https://doi.org/10.1007/s11240-017-1328-y

de Carvalho K, Bespalhok Filho JC, dos Santos TB, de Souza SGH, Vieira LGE, Pereira LFP, Domingues DS (2013) Nitrogen starvation, salt and heat stress in coffee (Coffea arabica L.): identification and validation of new genes for qPCR normalization. Mol Biotechnol 53: 315-325. https://doi.org/10.1007/s12033-012-9529-4

de Meaux J, Goebel U, Pop A, Mitchell-Olds T (2005) Allele-specific assay reveals functional variation in the chalcone synthase promoter of Arabidopsis thaliana that is compatible with neutral evolution. Plant Cell 17:676-690. https://doi.org/10.1105/tpc.104.027839

Denoeud F, Carretero-Paulet L, Dereeper A et al (2014) The coffee genome provides insight into the convergent evolution of caffeine biosynthesis. Science 345:1181-1184. https://doi.org/10.1126/ science. 1255274

Dussert S, Serret J, Bastos-Siqueira A, Morcillo F, Déchamp E, Rofidal V, Lashermes P, Etienne E, Joët T (2018) Integrative analysis of the late maturation programme and desiccation tolerance mechanisms in intermediate coffee seeds. J Exp Bot 69:1583-1597. https://doi. org $/ 10.1093 / \mathrm{jxb} / \mathrm{erx} 492$

Etienne H (2005) Somatic embryogenesis protocol: coffee (Coffea arabica L. and C. canephora P.). In: Jain SM, Gupta PK (eds) Protocol for somatic embryogenesis in woody plants. Springer, Dordrecht, pp 167-179

Fang ZW, Xu XY, Gao JF, Wang PK, Liu ZX, Feng BL (2015) Characterization of FeDREB 1 promoter involved in cold- and drought-inducible expression from common buckwheat (Fagopyrum esculentum). Genet Mol Res 14:7990-8000. https:// doi.org/10.4238/2015.July.17.7

Ferrão RG, Fonseca AFA, Silveira JSM, Ferrão MAG, Bragança SM (2000) EMCAPA 8141-Robustão Capixaba, variedade clonal de café conilon tolerante à seca, desenvolvida para o estado do Espírito Santo. Revista Ceres 273:555-560

Freire LP, Marraccini P, Rodrigues GC, Andrade AC (2013) Análise da expressão do gene da manose 6 fosfato redutase em cafeeiros submetidos ao deficit hídrico no campo. Coffee Sci 8:17-23

Galbiati M, Simoni L, Pavesi G, Cominelli E, Francia P, Vavasseur A, Nelson T, Bevan M, Tonelli C (2008) Gene trap lines identify Arabidopsis genes expressed in stomatal guard cells. Plant J 53: 750-762. https://doi.org/10.1111/j.1365-313X.2007.03371.x

Galbiati M, Matus J, Francia P, Rusconi F, Cañón P, Medina C, Conti L, Cominelli E, Tonelli C, Arce-Johnson P (2011) The grapevine guard cell-related VvMYB60 transcription factor is involved in the regulation of stomatal activity and is differentially expressed in response to ABA and osmotic stress. BMC Plant Biol 11:142. https://doi.org/ 10.1186/1471-2229-11-142

Gilmour SJ, Zarka DG, Stockinger EJ, Salazar MP, Houghton JM, Thomashow MF (1998) Low temperature regulation of the Arabidopsis CBF family of AP2 transcriptional activators as an early step in cold-induced COR gene expression. Plant J 16:433442. https://doi.org/10.1046/j.1365-313x.1998.00310.x

Gutha LR, Reddy AR (2008) Rice DREB1B promoter shows distinct stress-specific responses, and the overexpression of cDNA in tobacco confers improved abiotic and biotic stress tolerance. Plant Mol Biol 68:533-555. https://doi.org/10.1007/s11103-008-9391-8

Guttikonda SK, Valliyodan B, Neelakandan AK, Tran LSP, Kumar R, Quach TN, Voothuluru P, Gutierrez-Gonzalez JJ, Aldrich DL, Pallardy SG, Sharp RE, Ho THD, Nguyen HT (2014) Overexpression of AtDREB1D transcription factor improves drought tolerance in soybean. Mol Biol Rep 41:7995-8008. https://doi.org/10.1007/s11033-014-3695-3

Ha CV, Watanabe Y, Tran UT, le DT, Tanaka M, Nguyen KH, Seki M, Nguyen DV, Tran LSP (2015) Comparative analysis of root transcriptomes from two contrasting drought-responsive Williams 82 and DT2008 soybean cultivars under normal and dehydration 
conditions. Front Plant Sci 6:551. https://doi.org/10.3389/fpls.2015. 00551

Haake V, Cook D, Riechmann JL, Pineda O, Thomashow MF, Zhang JZ (2002) Transcription factor CBF4 is a regulator of drought adaptation in Arabidopsis. Plant Physiol 130:639-648. https://doi.org/10. 1104/pp.006478

Hachez C, Ohashi-Ito K, Dong J, Bergmann DC (2011) Differentiation of Arabidopsis guard cells: analysis of the networks incorporating the basic helix-loop-helix transcription factor, FAMA. Plant Physiol 155:1458-1472. https://doi.org/10.1104/pp.110.167718

Han L, Han Y-N, Xiao X-G (2013) Truncated cotton subtilase promoter directs guard cell-specific expression of foreign genes in tobacco and Arabidopsis. PLoS ONE 8:e59802. https://doi.org/10.1371/ journal.pone.0059802

Huang D, Jaradat MR, Wu W, Ambrose SJ, Ross AR, Abrams SR, Cutler AJ (2007) Structural analogs of ABA reveal novel features of ABA perception and signaling in Arabidopsis. Plant J 50:414 428. https:// doi.org/10.1111/j.1365-313X.2007.03056.X

Imbach P, Fung E, Hannah L, Navarro-Racines CE, Roubik DW, Ricketts TH, Harvey CA, Donatti CI, Läderach P, Locatelli B, Roehrdanz PR (2017) Coupling of pollination services and coffee suitability under climate change. Proc Natl Acad Sci U S A 114:10438-10442. https://doi.org/10.1073/pnas.1617940114

Janiak A, Kwaśniewski M, Szarejko I (2016) Gene expression regulation in roots under drought. J Exp Bot 67:1003-1014. https://doi.org/10. 1093/jxb/erv512

Jaramillo J, Muchugu E, Vega FE, Davis A, Borgemeister C, ChabiOlaye A (2011) Some like it hot: the influence and implications of climate change on coffee berry borer (Hypothenemus hampei) and coffee production in East Africa. PLoS ONE 6:e24528. https://doi. org/10.1371/journal.pone.0024528

Joshi R, Wani SH, Singh B, Bohra A, Dar ZA, Lone AA, Pareek A, Singla-Pareek SL (2016) Transcription factors and plants response to drought stress: current understanding and future directions. Front Plant Sci 7:1029. https://doi.org/10.3389/fpls.2016.01029

Jovanović Ž, Stanisavljević N, Mikić A, Radović S, Maksimović V (2013) The expression of drought responsive element binding protein $(D R E B 2 A)$ related gene from pea (Pisum sativum L.) as affected by water stress. Aust J Crop Sci 7:1590-1596

Khan MS (2011) The role of DREB transcription factors in abiotic stress tolerance of plants. Biotechnol Biotechnol Equip 25:2433-2442. https://doi.org/10.5504/BBEQ.2011.0072

Lashermes P, Andrade AC, Etienne H (2008) Genomics of coffee, one of the world's largest traded commodities. In: Moore H, Ming R (eds) Genomics of tropical crop plants. Springer, New York, pp 203-226. https://doi.org/10.1007/978-0-387-71219-2_9

Lata C, Prasad M (2011) Role of DREBS in regulation of abiotic stress responses in plants. J Exp Bot 62:4731-4748. https://doi.org/10. 1093/jxb/err2 10

Lee SJ, Kang JY, Park HJ, Kim MD, Bae MS, Choi HI, Kim SY (2010) DREB2C interacts with ABF2, a bZIP protein regulating abscisic acid-responsive gene expression, and its overexpression affects abscisic acid sensitivity. Plant Physiol 153:716-727. https://doi. org/10.1104/pp.110.154617

Leonhardt N, Kwak JM, Robert N, Waner D, Leonhardt G, Schroeder JI (2004) Microarray expression analyses of Arabidopsis guard cells and isolation of a recessive abscisic acid hypersensitive protein phosphatase 2C mutant. Plant Cell 16:596-615. https://doi.org/10. 1105/tpc.019000

Li D, Zhang Y, Hu X, Shen X, Ma L, Su Z, Wang T, Dong J (2011) Transcriptional profiling of Medicago truncatula under salt stress identified a novel $C B F$ transcription factor $M t C B F 4$ that plays an important role in abiotic stress responses. BMC Plant Biol 11:109. https://doi.org/10.1186/1471-2229-11-109

Li H, Wang Y, Wu M, Li L, Li C, Han Z, Yuan J, Chen C, Song W, Wang C (2017) Genome-wide identification of AP2/ERF transcription factors in cauliflower and expression profiling of the ERF family under salt and drought stresses. Front Plant Sci 8:946. https://doi. org/10.3389/fpls.2017.00946

Lin C, Mueller LA, Carthy JM, Crouzillat D, Pétiard V, Tanksley SD (2005) Coffee and tomato share common gene repertoires as revealed by deep sequencing of seed and cherry transcripts. Theor Appl Genet 112:114-130. https://doi.org/10.1007/s00122-005-0112-2

Liu Q et al (1998) Two transcription factors, DREB1 and DREB2, with an EREBP/AP2 DNA binding domain separate two cellular signal transduction pathways in drought- and low-temperature-responsive gene expression, respectively, in Arabidopsis. Plant Cell 10:391406. https://doi.org/10.1105/tpc.10.8.1391

Liu S, Wang X, Wang H, Xin H, Yang X, Yan J, Li J, Tran LSP, Shinozaki K, Yamaguchi-Shinozaki K, Qin F (2013) Genome-wide analysis of $Z m D R E B$ genes and their association with natural variation in drought tolerance at seedling stage of Zea mays L. PLoS Genet 9: e1003790. https://doi.org/10.1371/journal.pgen.1003790

Lorenz WW, Alba R, Yu YS, Bordeaux JM, Simões M, Dean JFD (2011) Microarray analysis and scale-free gene networks identify candidate regulators in drought-stressed roots of loblolly pine ( $P$. taeda L.). BMC Genomics 12:264. https://doi.org/10.1186/1471-2164-12-264

Marraccini P, Freire LP, Alves GSC, Vieira NG, Vinecky F, Elbelt S, Ramos HJO, Montagnon C, Vieira LGE, Leroy T, Pot D, Silva VA, Rodrigues GC, Andrade AC (2011) RBCS1 expression in coffee: Coffea orthologs, Coffea arabica homeologs, and expression variability between genotypes and under drought stress. BMC Plant Biol 11:85. https://doi.org/10.1186/1471-2229-11-85

Marraccini P, Vinecky F, Alves GSC, Ramos HJO, Elbelt S, Vieira NG, Carneiro FA, Sujii PS, Alekcevetch JC, Silva VA, DaMatta FM, Ferrao MAG, Leroy T, Pot D, Vieira LGE, da Silva FR, Andrade AC (2012) Differentially expressed genes and proteins upon drought acclimation in tolerant and sensitive genotypes of Coffea canephora. J Exp Bot 63:4191-4212. https://doi.org/10.1093/jxb/ers103

Mofatto LS, Carneiro FA, Vieira NG, Duarte KE, Vidal RO, Alekcevetch JC, Cotta MG, Verdeil JL, Lapeyre-Montes F, Lartaud M, Leroy T, de Bellis F, Pot D, Rodrigues GC, Carazzolle MF, Pereira GAG, Andrade AC, Marraccini P (2016) Identification of candidate genes for drought tolerance in coffee by high-throughput sequencing in the shoot apex of different Coffea arabica cultivars. BMC Plant Biol 16: 94. https://doi.org/10.1186/s12870-016-0777-5

Mondego JMC, Vidal RO, Carazzolle MF, Tokuda EK, Parizzi LP, Costa GGL, Pereira LFP, Andrade AC, Colombo CA, Vieira LGE, Pereira GAG, Brazilian Coffee Genome Project Consortium (2011) An EST-based analysis identifies new genes and reveals distinctive gene expression features of Coffea arabica and Coffea canephora. BMC Plant Biol 11:30. https://doi.org/10.1186/1471-2229-11-30

Mueller L, Strickler S, Domingues D, Pereira LFP, Andrade AC, Marraccini P, Ming R, Wai J, Albert V, Giuliano G, Descombes P, Moine D, Guyot R, Poncet V, Hamon P, Hamon S, Tranchant C, de Kochko A, Lepelley M, Rigoreau M, Crouzillat D (2015) Towards a better understanding of the Coffea arabica genome structure. In: Association for Science and Information on Coffee ASIC (ed) Proceedings of the $25^{\text {th }}$ International Conference on Coffee Science, Armenia (Colombia)

Murashige T, Skoog F (1962) A revised medium for rapid growth and bio assays with tobacco tissue cultures. Physiol Plant 15:473-497. https://doi.org/10.1111/j.1399-3054.1962.tb08052.x

Nakano T, Suzuki K, Fujimura T, Shinshi H (2006) Genome-wide analysis of the ERF gene family in Arabidopsis and rice. Plant Physiol 140:411-432. https://doi.org/10.1104/pp.105.073783

Pinheiro HA, DaMatta FM, Chaves ARM, Loureiro ME, Ducatti C (2005) Drought tolerance is associated with rooting depth and stomatal control of water use in clones of Coffea canephora. Ann Bot 96:101-108. https://doi.org/10.1093/aob/mci154

Poncet V, Rondeau M, Tranchant C, Cayrel A, Hamon S, de Kochko A, Hamon P (2006) SSR mining in coffee tree EST databases: potential 
use of EST-SSRs as marker across Coffea genus. Mol Gen Genet 276:436-449. https://doi.org/10.1007/s00438-006-0153-5

Rusconi F, Simeoni F, Francia P, Cominelli E, Conti L, Riboni M, Simoni L, Martin CR, Tonelli C, Galbiati M (2013) The Arabidopsis thaliana MYB60 promoter provides a tool for the spatio-temporal control of gene expression in stomatal guard cells. J Exp Bot 64: 3361-3371. https://doi.org/10.1093/jxb/ert180

Sakuma Y, Liu Q, Dubouzet JG, Abe H, Shinozaki K, YamaguchiShinozaki K (2002) DNA-binding specificity of the ERF/AP2 domain of Arabidopsis DREBs, transcription factors involved in dehydration- and cold-inducible gene expression. Biochem Bioph Res Co 290:998-1009. https://doi.org/10.1006/bbrc.2001.6299

Shinozaki K, Yamaguchi-Shinozaki K (2007) Gene networks involved in drought stress response and tolerance. J Exp Bot 58:221-227. https://doi.org/10.1093/jxb/erl164

Silva EA, Mazzafera P, Brunini O, Sakai E, Arruda FB, Mattoso LHC, Carvalho CRL, Pires RCM (2005) The influence of water management and environmental conditions on the chemical composition and beverage quality of coffee beans. Braz J Plant Physiol 17: 229-238. https://doi.org/10.1590/S1677-04202005000200006

Simkin AJ, Moreau H, Kuntz M, Pagny G, Lin C, Tanksley S, McCarthy J (2008) An investigation of carotenoid biosynthesis in Coffea canephora and Coffea arabica. J Plant Physiol 165:1087-1106. https://doi.org/10.1016/j.jplph.2007.06.016

Sun S, Yu JP, Chen F, Zhao TJ, Fang XH, Li YQ, Sui SF (2008) TINY, a dehydration-responsive element (DRE)-binding protein-like transcription factor connecting the DRE- and ethylene-responsive element-mediated signaling pathways in Arabidopsis. J Biol Chem 283:6261-6271. https://doi.org/10. 1074/jbc.M706800200

Takeshima R, Hayashi T, Zhu J, Zhao C, Xu M, Yamaguchi N, Sayama T, Ishimoto M, Kong L, Shi X, Liu B, Tian Z, Yamada T, Kong F, Abe $J$ (2016) A soybean quantitative trait locus that promotes FLOWERING under long days is identified as FT5a, a FLOWERING LOCUS T ortholog. J Exp Bot 67:5247-5258. https://doi.org/10.1093/jxb/erw283

Thioune EH, McCarthy J, Gallagher T, Osborne B (2017) A humidity shock leads to rapid, temperature dependent changes in coffee leaf physiology and gene expression. Tree Physiol 37:367-379. https:// doi.org/10.1093/treephys/tpw129

Van der Vossen H, Bertrand B, Charrier A (2015) Next generation variety development for sustainable production of arabica coffee (Coffea arabica L.): a review. Euphytica 204:243-256. https://doi.org/10. 1007/s10681-015-1398-z

Vidal RO, Mondego JMC, Pot D, Ambrosio AB, Andrade AC, Pereira LFP, Colombo CA, Vieira LGE, Carazzolle MF, Pereira GAG (2010) A high-throughput data mining of single nucleotide polymorphisms in Coffea species expressed sequence tags suggests differential homeologous gene expression in the allotetraploid Coffea arabica. Plant Physiol 154:1053-1066. https://doi.org/10.1104/pp. 110.162438

Vieira LGE, Andrade AC, Colombo CA, Moraes AAH, Metha A, Oliveira AC, and the Brazilian coffee genome project et al (2006) Brazilian coffee genome project: an EST-based genomic resource.
Braz J Plant Physiol 18:95-108. https://doi.org/10.1590/S167704202006000100008

Vieira NG, Carneiro FA, Sujii PS, Alekcevetch JC, Freire LP, Vinecky F, Elbelt S, Silva VA, DaMatta FM, Ferrão MAG, Marraccini P, Andrade AC (2013) Different molecular mechanisms account for drought tolerance in Coffea canephora var. Conilon. Trop Plant Biol 6:181-190. https://doi.org/10.1007/s12042-013-9126-0

Vinecky F, da Silva FR, Andrade AC (2012) Análise in silico das bibliotecas de cDNA SH2 e SH3 para a identificação de genes responsivos à seca em cafeeiro. Coffee Sci 7:1-19. https://doi.org/ 10.25186/cs.v7i1.155

Vinecky F, Davrieux F, Mera AC, Alves GSC, Lavagnini G, Leroy T, Bonnot F, Rocha OC, Bartholo GF, Guerra AF, Rodrigues GC, Marraccini P, Andrade AC (2017) Controlled irrigation and nitrogen, phosphorous and potassium fertilization affect the biochemical composition and quality of Arabica coffee beans. J Agric Sci 155: 902-918. https://doi.org/10.1017/S0021859616000988

Virlouvet L, Fromm M (2015) Physiological and transcriptional memory in guard cells during repetitive dehydration stress. New Phytol 205: 596-607. https://doi.org/10.1111/nph.13080

Wang Q, Guan Y, Wu Y, Chen H, Chen F, Chu C (2008) Overexpression of a rice $O S D R E B 1 F$ gene increases salt, drought, and low temperature tolerance in both Arabidopsis and rice. Plant Mol Biol 67:589602. https://doi.org/10.1007/s11103-008-9340-6

Wang RS, Pandey S, Li S, Gookin TE, Zhao Z, Albert R, Assmann SM (2011) Common and unique elements of the ABA-regulated transcriptome of Arabidopsis guard cells. BMC Genomics 12:216. https://doi.org/10.1186/1471-2164-12-216

Xiao H, Tattersall E, Siddiqua M, Cramer GR, Nassuth A (2008) CBF4 is a unique member of the CBF transcription factor family of Vitis vinifera and Vitis riparia. Plant Cell Environ 31:1-10. https://doi. org/10.1111/j.1365-3040.2007.01741.x

Yang Y, Costa A, Leonhardt N, Siegel RS, Schroeder JI (2008) Isolation of a strong Arabidopsis guard cell promoter and its potential as a research tool. Plant Methods 4:6. https://doi.org/10.1186/17464811-4-6

Zandkarimi H, Ebadi A, Salami SA, Alizade H, Baisakh N (2015) Analyzing the expression profile of $A R E B / A B F$ and $D R E B / C B F$ genes under drought and salinity stresses in grape (Vitis vinifera L.). PLoS ONE 10:e0134288. https://doi.org/10.1371/journal. pone. 0134288

Zarka DG, Vogel JT, Cook D, Thomashow MF (2003) Cold induction of Arabidopsis CBF genes involves multiple ICE (inducer of CBF expression) promoter elements and a cold-regulatory circuit that is desensitized by low temperature. Plant Physiol 133:910-918. https://doi.org/10.1104/pp.103.027169

Zhang X, Liu X, Zhang D, Tang H, Sun B, Li C, Hao L, Liu C, Li Y, Shi Y, Xie X, Song Y, Wang T, Li Y (2017) Genome-wide identification of gene expression in contrasting maize inbred lines under field drought conditions reveals the significance of transcription factors in drought tolerance. PLoS ONE 12:e0179477. https://doi.org/10. 1371/journal.pone.0179477

Publisher's Note Springer Nature remains neutral with regard to jurisdictional claims in published maps and institutional affiliations. 